\title{
Warming of Antarctica as a Degassing Consequence
}

\author{
Alex Retejum \\ Department of Geography, Lomonosov Moscow State University, Moscow, Russia \\ Email: aretejum@yandex.ru
}

How to cite this paper: Retejum, A. (2021). Warming of Antarctica as a Degassing Consequence. Journal of Geoscience and Environment Protection, 9, 17-41.

https://doi.org/10.4236/gep.2021.92002

Received: May 27, 2020

Accepted: February 4, 2021

Published: February 7, 2021

Copyright (C) 2021 by author(s) and Scientific Research Publishing Inc. This work is licensed under the Creative Commons Attribution International License (CC BY 4.0).

http://creativecommons.org/licenses/by/4.0/

\begin{abstract}
The warming of Antarctica observed in recent years is one of the consequences of deep degassing associated with the northward drift of the Earth's core. Ascending streams of hydrogen and other gases move along the tectonic faults of the lithosphere. When they get into an oxidizing environment, there is an increase in the amount of water in the ocean and air, which is accompanied by a decrease in oxygen concentrations and the release of huge amounts of energy. The provisions of the proposed theory were tested using the method of mental critical experiment. The reality of atmospheric effects of subsurface degassing is confirmed by the facts of synchronous destruction of ozone in the stratosphere and an increase in the temperature of the surface air layer. These events usually coincide with releases of ozone-depleting and heat-generating hydrogen from the subsurface.
\end{abstract}

\section{Keywords}

Antarctica, Climate Warming, Hydrogen Degassing, Earth's Core Drift

\section{Introduction}

For the first time in the history of meteorological observations in the Antarctica, maximum air temperature above $20^{\circ}$ was recorded at the Argentine station Marambio on February 9, 2020. The previous record dated March 24, 2015, was $17.5^{\circ}$ (data from Esperanza station, which is also located at the northern tip of the Antarctic Peninsula). It is obvious that now we are facing the process of accelerated warming of the southern polar region of the globe. A scientific explanation of the phenomenon is only possible if we elucidate the causes of the strongest heating of the surface air layer in a specific place and at a specific time. A comprehensive answer to this question is offered by an array of facts through their generalization and deep analysis confirming that this is a consequence of 
deep degassing of hydrogen caused by the accelerated drift of the Earth's core from the Southern Hemisphere to the Northern. As follows from the analysis of weather conditions in the region of the Antarctic Peninsula, temperature anomalies of 2020 and 2015 are characterized by sudden onset and rapid disappearance (Figure 1).

As a rule, sharp air temperature changes cause deep cyclones, but in the cases considered they are in no way associated with the passage of atmospheric fronts (Figure 2).

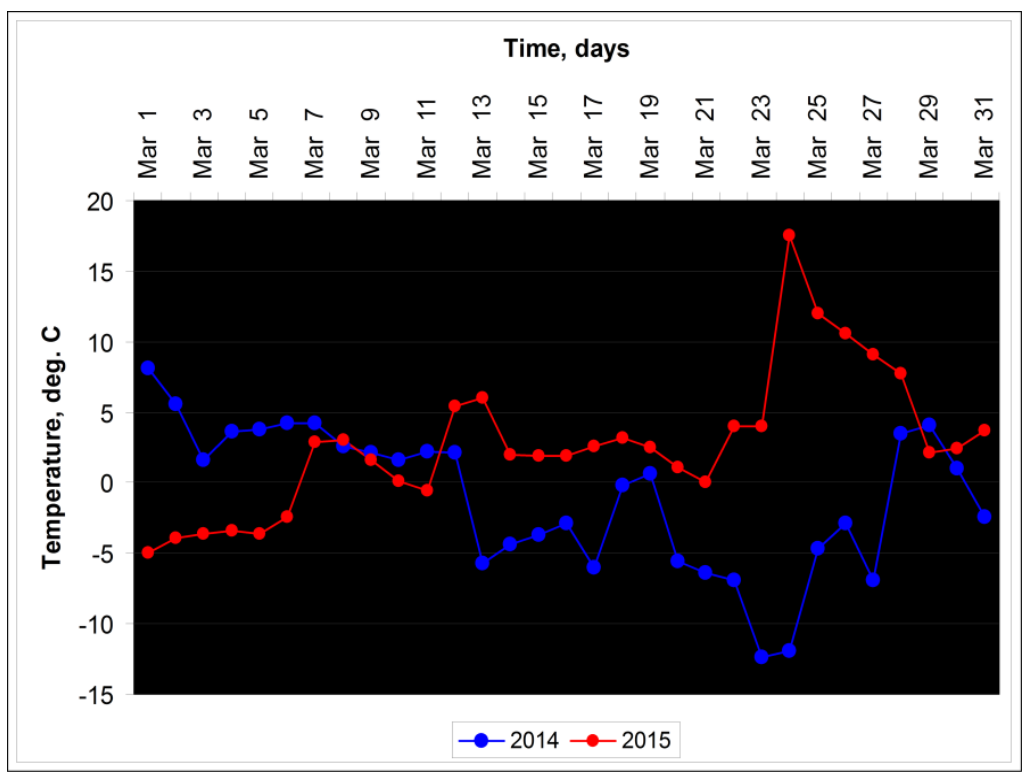

Source: according to TuTiempo.net, https://www.tutiempo.net/clima/ws-889630.html.

Figure 1. Air temperature in the north of the Antarctic Peninsula in March 2014 and 2015 (Esperanza station).

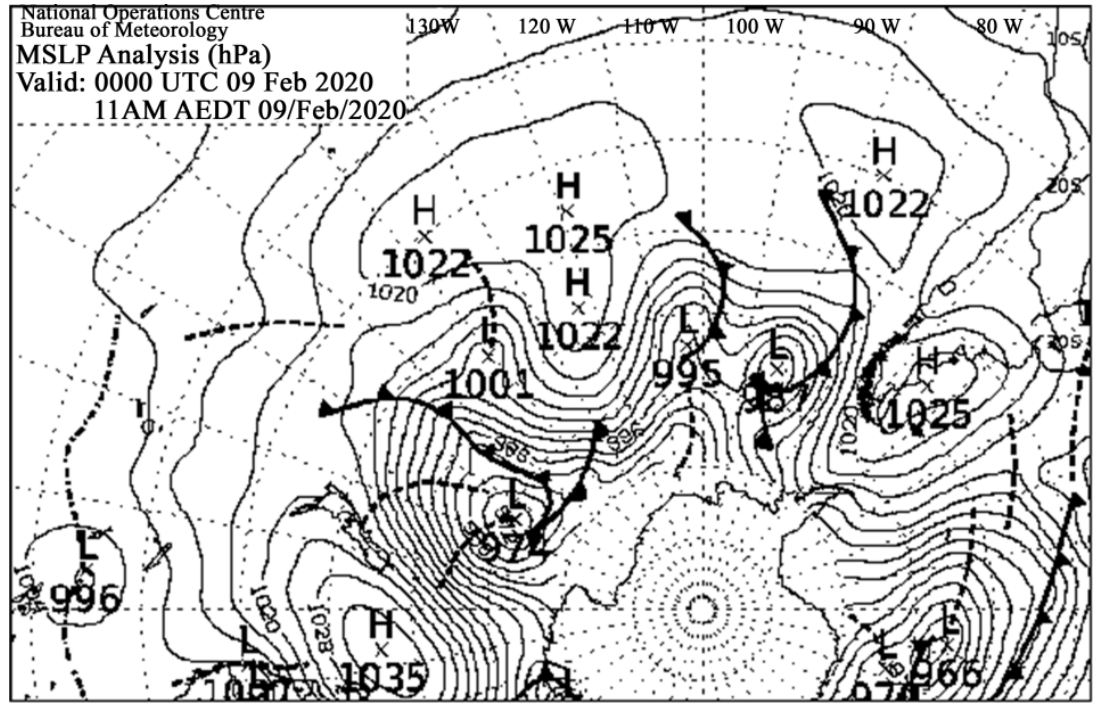

Source: MSLP Analysis, Pacific Ocean, Bureau of Meteorology, Australian Government, http://www.bom.gov.au/cgi-bin/charts/charts.view.

Figure 2. Synoptic map of the South Pacific on February 9, 2020. 
About a hundred active volcanoes were found under the ice sheet (Iverson et al., 2017; Van Wyk de Vries et al., 2017; Seroussi et al., 2017; Loose et al., 2018); it is, therefore, reasonable to suggest that atmospheric warming is determined by subsoil heat exchange. In view of recent geological findings, search for the causes behind climate change moved to a new plane, but this did not solve the problem. It is necessary to know the source and mechanism of energy transfer. Ways to manage uncertainty are promised by the theory of deep degassing based on an empirical generalization conducted by Syvorotkin, 2010) and later supplemented by Barkin (2016) and the author of this article. The bottom line is as follows. Upward flows of hydrogen and other gases move along tectonic faults and fissures of the lithosphere from the mantle and core of the Earth. When they enter the oxidizing environment, the amount of water in the ocean and air dramatically increase, which is accompanied by reduced oxygen concentrations and the release of gigantic amounts of energy.

The continent is split into two parts by the Western Antarctic Rift system (Figure 3). West Antarctica is moving away from East Antarctica over tens of millions of years (Dalziel, 2006; Kalberg et al., 2015). As Antarctica has been found to be the area with the highest concentration of volcanoes, this structure can be viewed as the key link in the global system of linear depressions formed during the stretching of the Earth's crust. The sixth continent is surrounded by a dense network of tectonic faults.

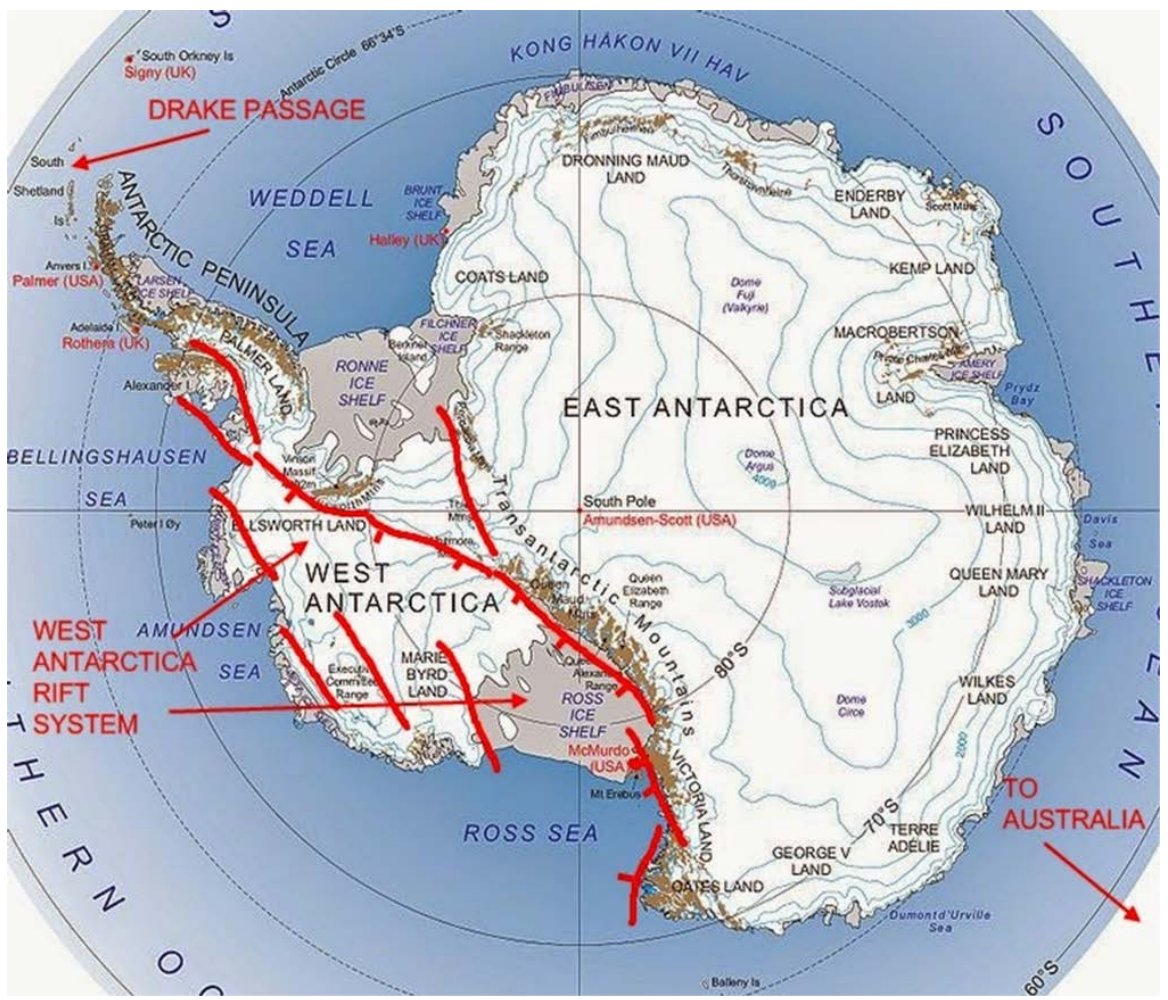

Source: RIGibson,

http://historyoftheearthcalendar.blogspot.com/2014/12/december-13-antarctica-freezes.html.

Figure 3. Antarctic rift and major tectonic faults. 


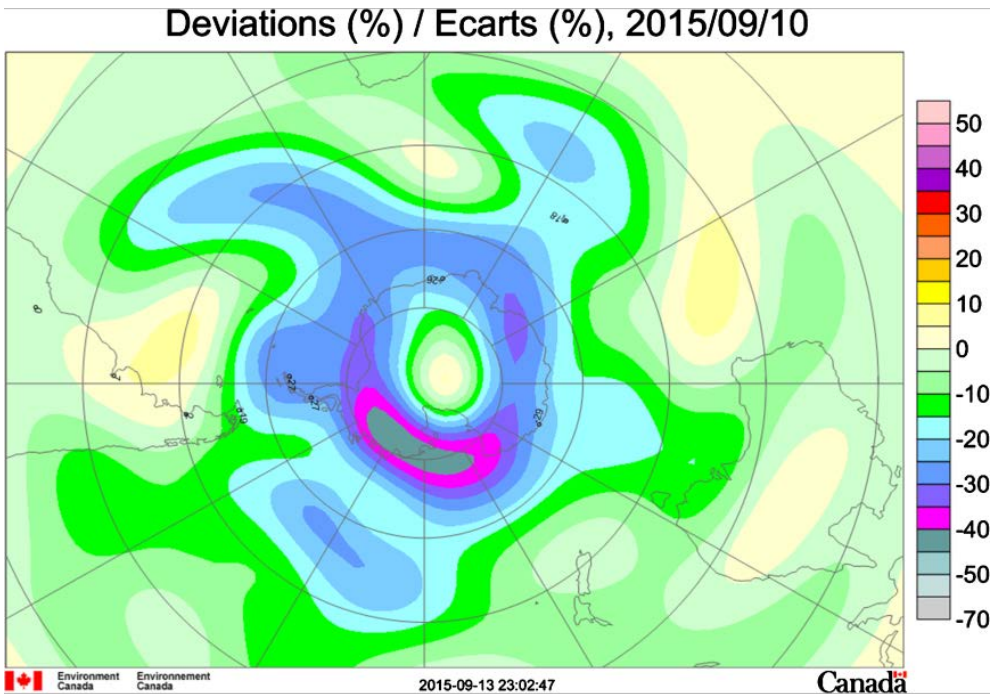

Source: Environment Canada, https://exp-studies.tor.ec.gc.ca/cgi-bin/selectMap.

Figure 4. Large negative anomaly in the total atmospheric ozone content over the Western Antarctic Rift system and tectonic faults along the continent borders (September 10, 2015).

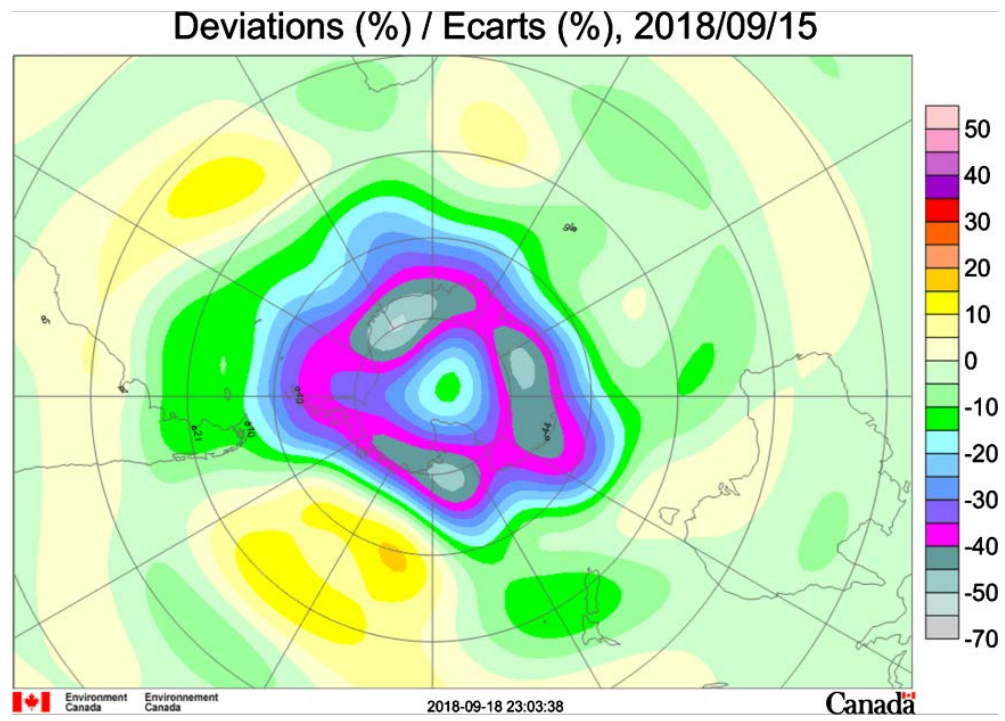

Source: Ibid.

Figure 5. A complex negative anomaly in the total atmospheric ozone content over the Earth's crust dislocation zones in Antarctica (September 15, 2018).

The hard shell ruptures are manifested in negative anomalies in the total atmospheric ozone content, which coincide in shape with the dislocation zones (Figure 4 \& Figure 5).

The proposed theory can be verified using the method of mental critical experiment, i.e., the test, the results of which do receive an unambiguous interpretation. First, the reality of the atmospheric effects of subsoil degassing must be confirmed by the facts of synchronous destruction of ozone in the stratosphere and increased temperature of the surface air layer, and then it should be demonstrated that these events usually coincide in time with emissions of ozone-depleting and 
heat-generating hydrogen from the Earth's subsurface. Below are the results of a series of critical experiments.

\section{Heat Waves and Negative Ozone Anomalies}

Temperature records of 2020 and 2015 were naturally observed just at the time of rather large anomalies of the total atmospheric ozone content in the region of the Antarctic Peninsula (Figure 6 \& Figure 7).

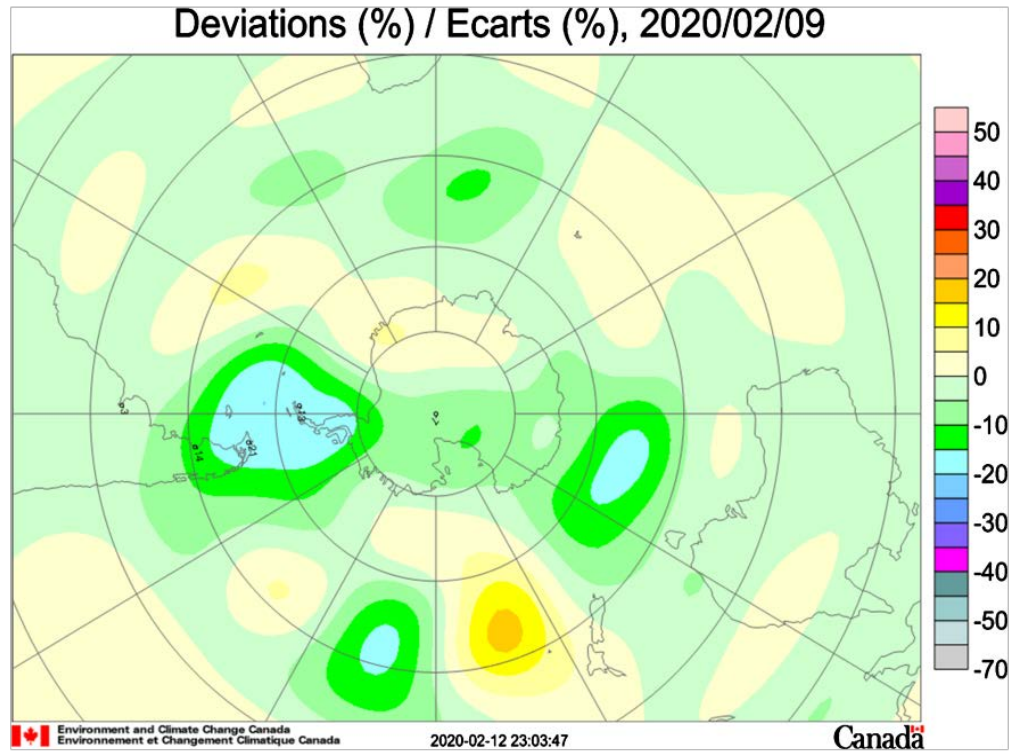

Source: Ibid.

Figure 6. Total atmospheric ozone content anomaly over the Antarctic Peninsula on February 9, 2020.

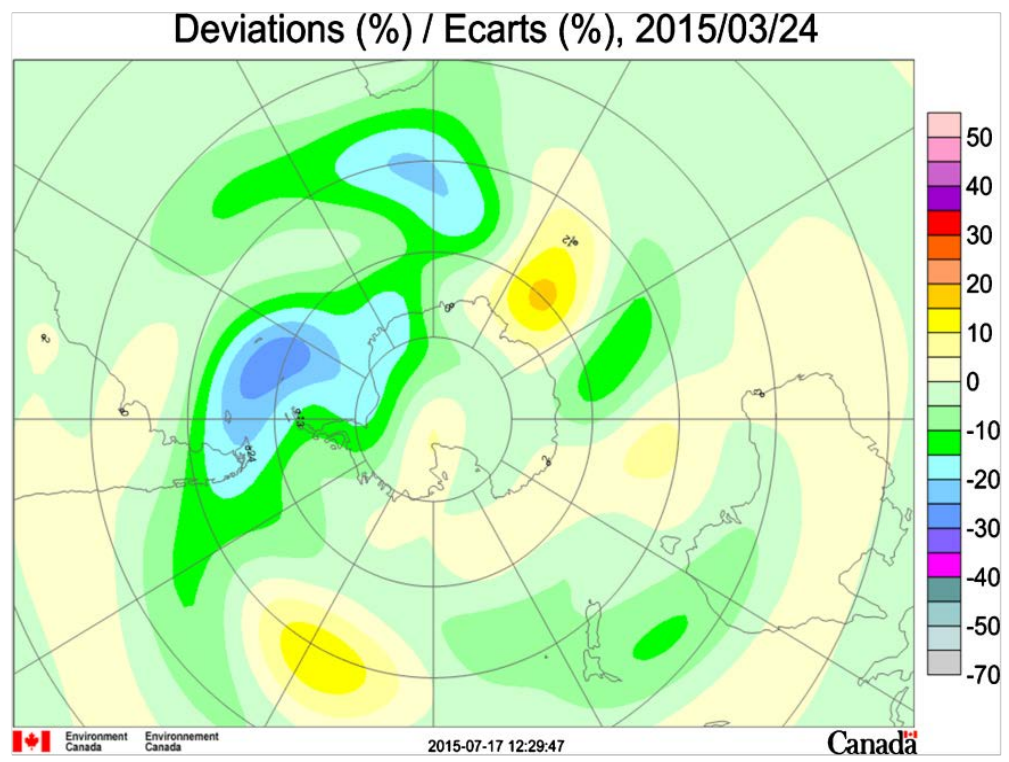

Source: Ibid.

Figure 7. Total atmospheric ozone content anomaly over the Antarctic Peninsula March $24,2015$. 
Total atmospheric ozone content decreases during the periods of high seismic activity. In January 2000-2020, 32 earthquakes with $M \geq 3$ were recorded in the Antarctic sector. Negative ozone anomalies were observed in 29 (91\%) cases (Figures 8-10).

The contrasts of the state of the atmosphere in the months of high and low seismic activity are significant (Figure $11 \&$ Figure 12).

There is obvious interdependence between the states of the atmosphere and lithosphere. The conclusion about the coupled nature of their changes is supported by numerous episodes of synchronization between the drop of the total ozone content and increased air temperature maximum during earthquakes (Figure 13 \& Figure 14).

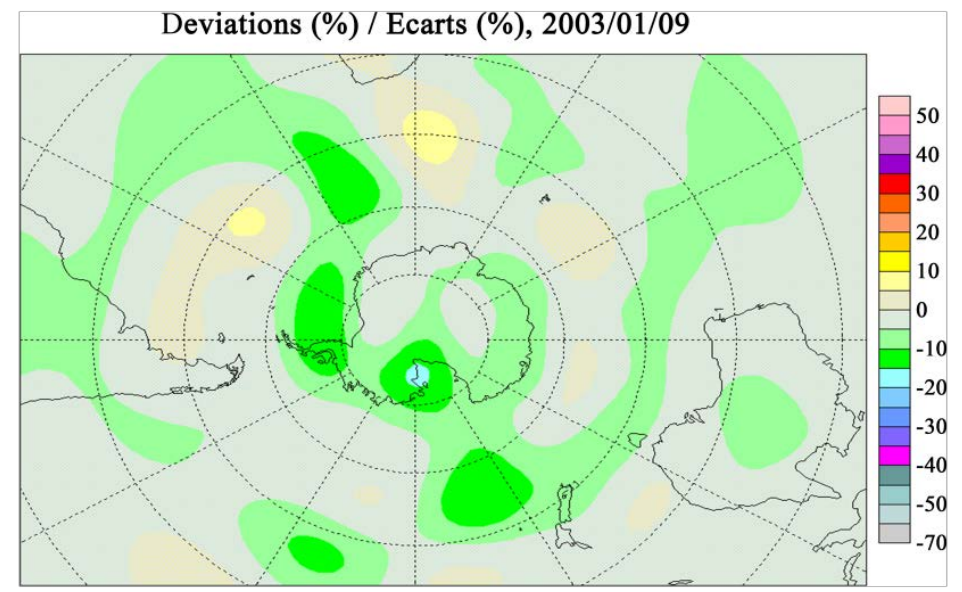

Source: Ibid. and International Seismological Center data, http://www.isc.ac.uk/iscbulletin/search/catalogue/.

Figure 8. Total atmospheric ozone content anomalies above the Antarctic on January 9, 2003, on the day of the earthquake with M 5.1 (the epicenter with coordinates $60.03^{\circ} \mathrm{N}$ and $57.98^{\circ} \mathrm{W}$ is located at the northern end of Antarctic Peninsula).

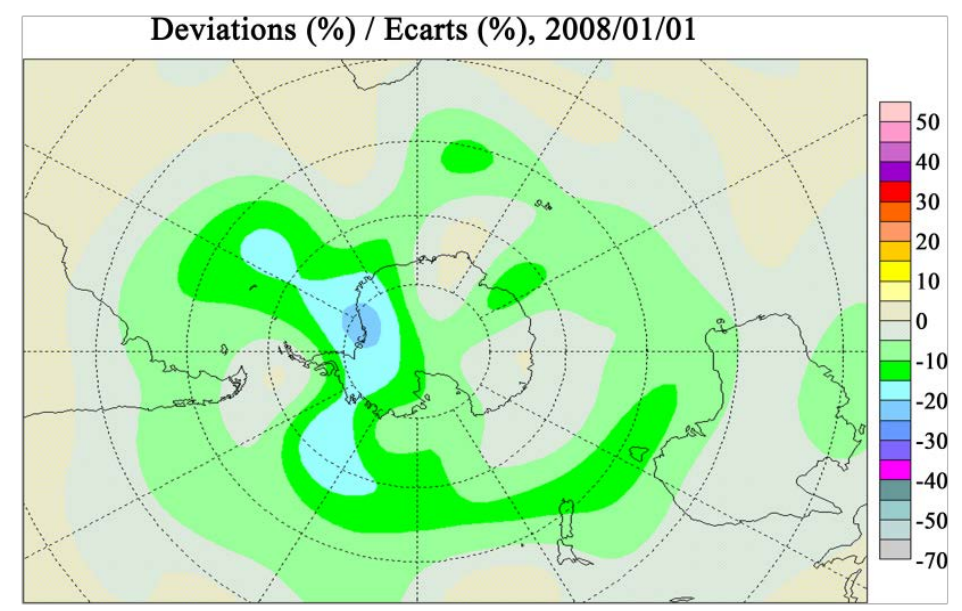

Source: Ibid.

Figure 9. Total atmospheric ozone content anomalies above the Antarctica on January 1, 2008 before the earthquake with M 4.4 (the epicenter with coordinates $61.24^{\circ} \mathrm{N}$ and $58.52^{\circ} \mathrm{W}$ is located at the northern tip of the Antarctic Peninsula). 


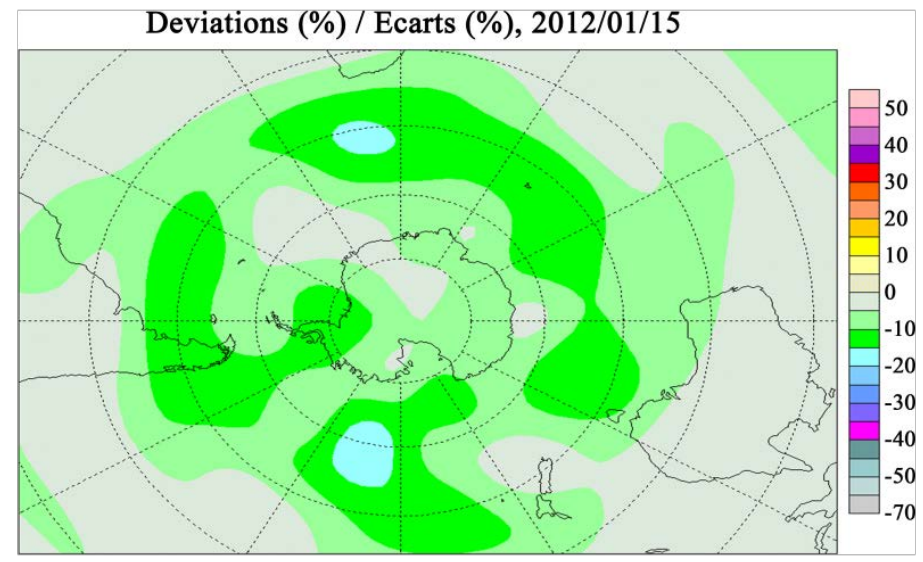

Source: Ibid.

Figure 10. Total atmospheric ozone content anomalies over the Antarctica on January 15, 2012 with a series of earthquakes with $\mathrm{M}$ 4.1 - 6.4 (epicenters with coordinates: $60.7^{\circ} \mathrm{N}-61.3^{\circ} \mathrm{N}$ and $53.8^{\circ} \mathrm{W}-56.6^{\circ} \mathrm{W}$ located at the northern tip of the Antarctic Peninsula).

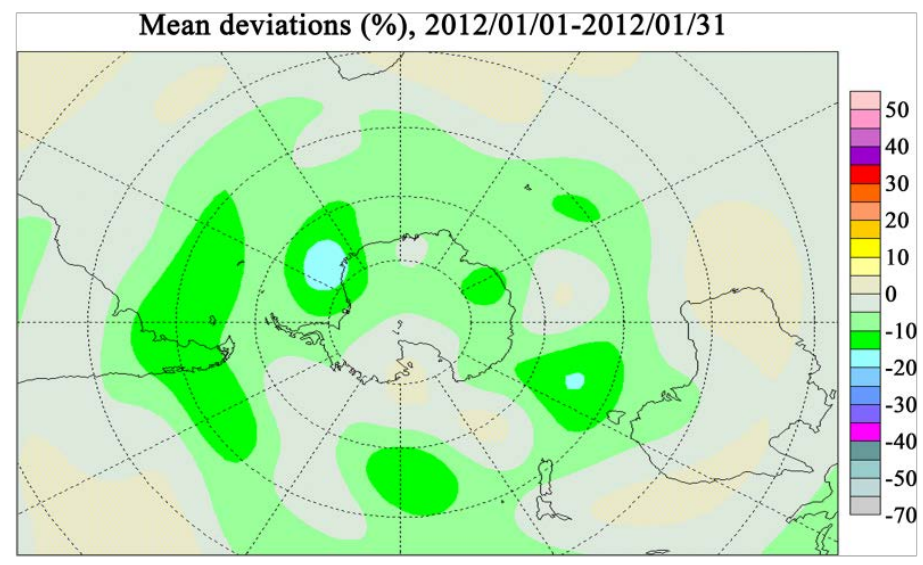

Source: Ibid.

Figure 11. Total atmospheric ozone content anomalies over the Antarctica in January 2012, when 20 earthquakes with M 4.0 - 6.4 occurred in the Antarctic Peninsula region (epicenter coordinates: $60.4^{\circ} \mathrm{N}-62.5^{\circ} \mathrm{N}, 51.1^{\circ} \mathrm{W}-57.6^{\circ} \mathrm{W}$ ).

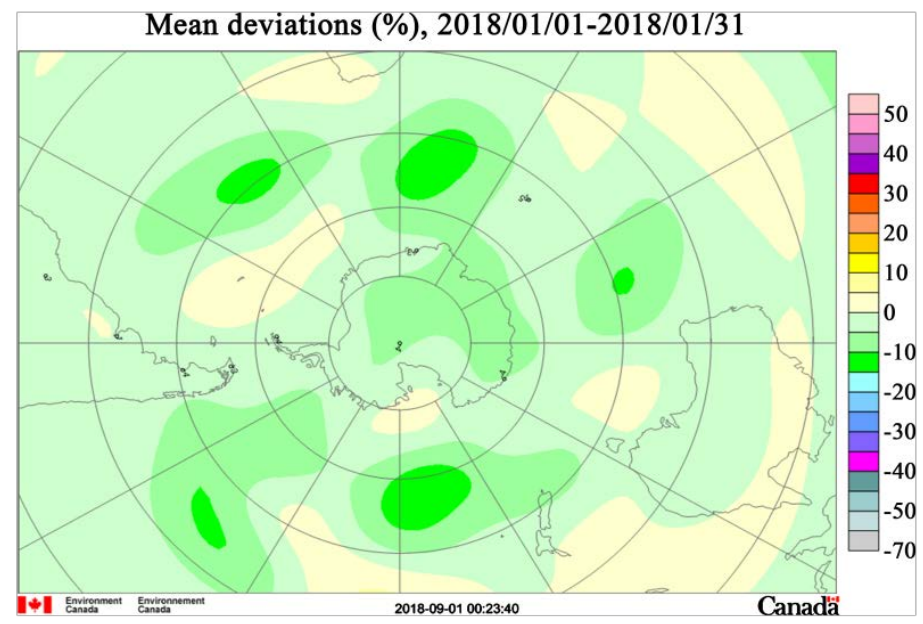

Source: Ibid.

Figure 12. Minor deviations of the total atmospheric ozone content from normal above the Antarctica in January 2018, when no earthquakes with $M \geq 3$ were recorded in the Antarctic Peninsula region. 


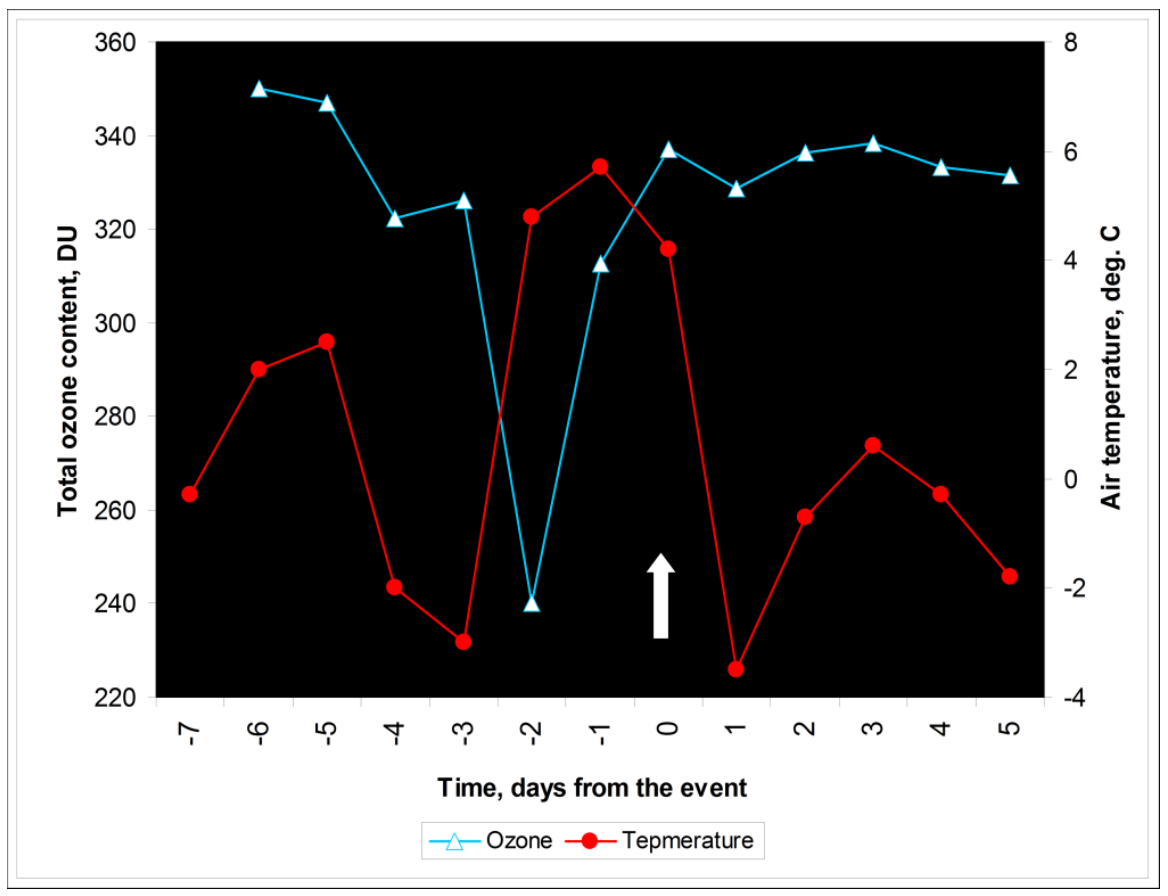

Source: According to the International Seismological Center, TuTiempo.net and Goddard Space Flight Center, http://www.isc.ac.uk/iscbulletin/search/catalogue/; http://www.nasa.gov/goddard.

Figure 13. The reaction of the surface air layer and the stratosphere to three earthquakes in the Scotia Sea (coordinates of epicenters: $60.45^{\circ} \mathrm{S}, 52.31^{\circ} \mathrm{W} ; 60.43^{\circ} \mathrm{S}, 51.74^{\circ} \mathrm{W} ; 60.45^{\circ} \mathrm{S}$, $51.49^{\circ} \mathrm{W}$ ) on December 8, 2007. Event time is indicated by an arrow (observations at Marambio Base).

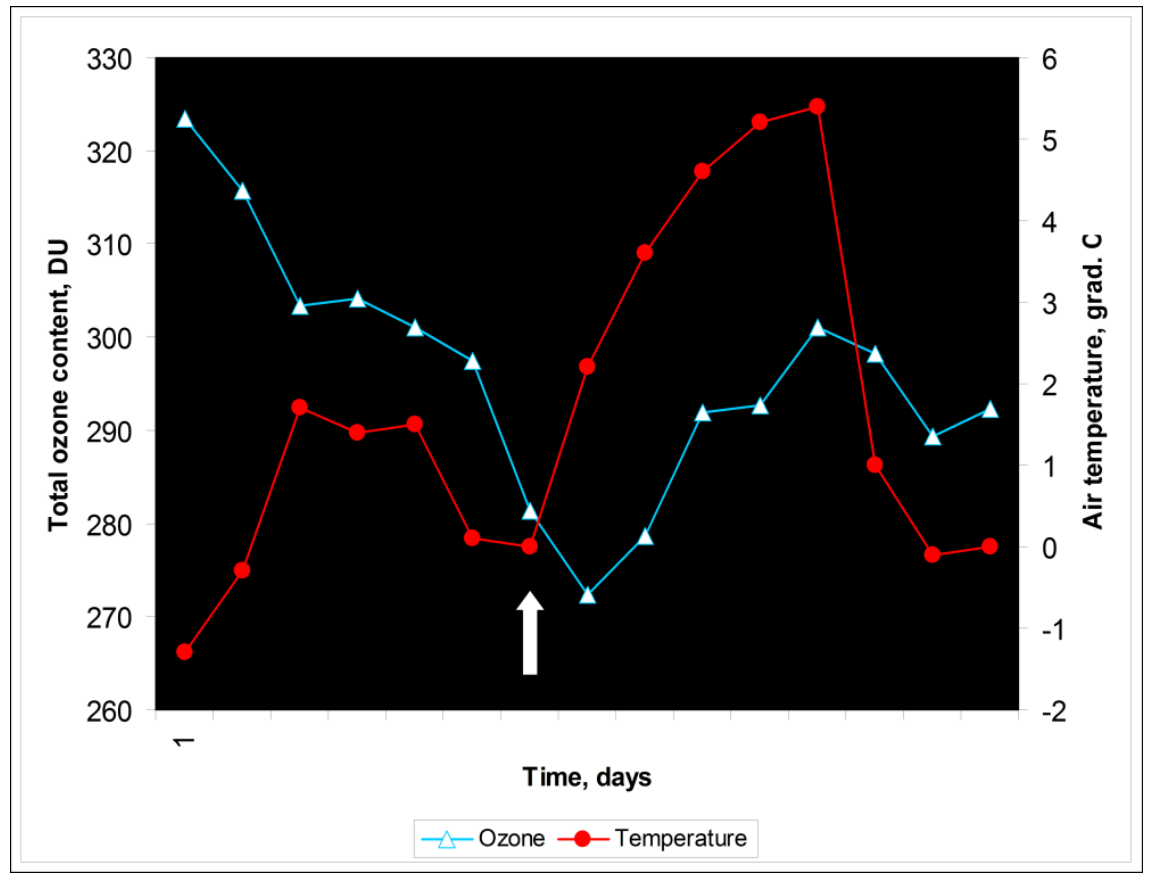

Source: Ibid.

Figure 14. The reaction of the surface air layer and the stratosphere to the earthquake with M 4.0 in the Scotia Sea (coordinates of the epicenter: $60.41^{\circ} \mathrm{S}, 52.41^{\circ} \mathrm{W}$ ) on January 25,2017 . Event time is indicated by an arrow (observations at Marambio Base). 


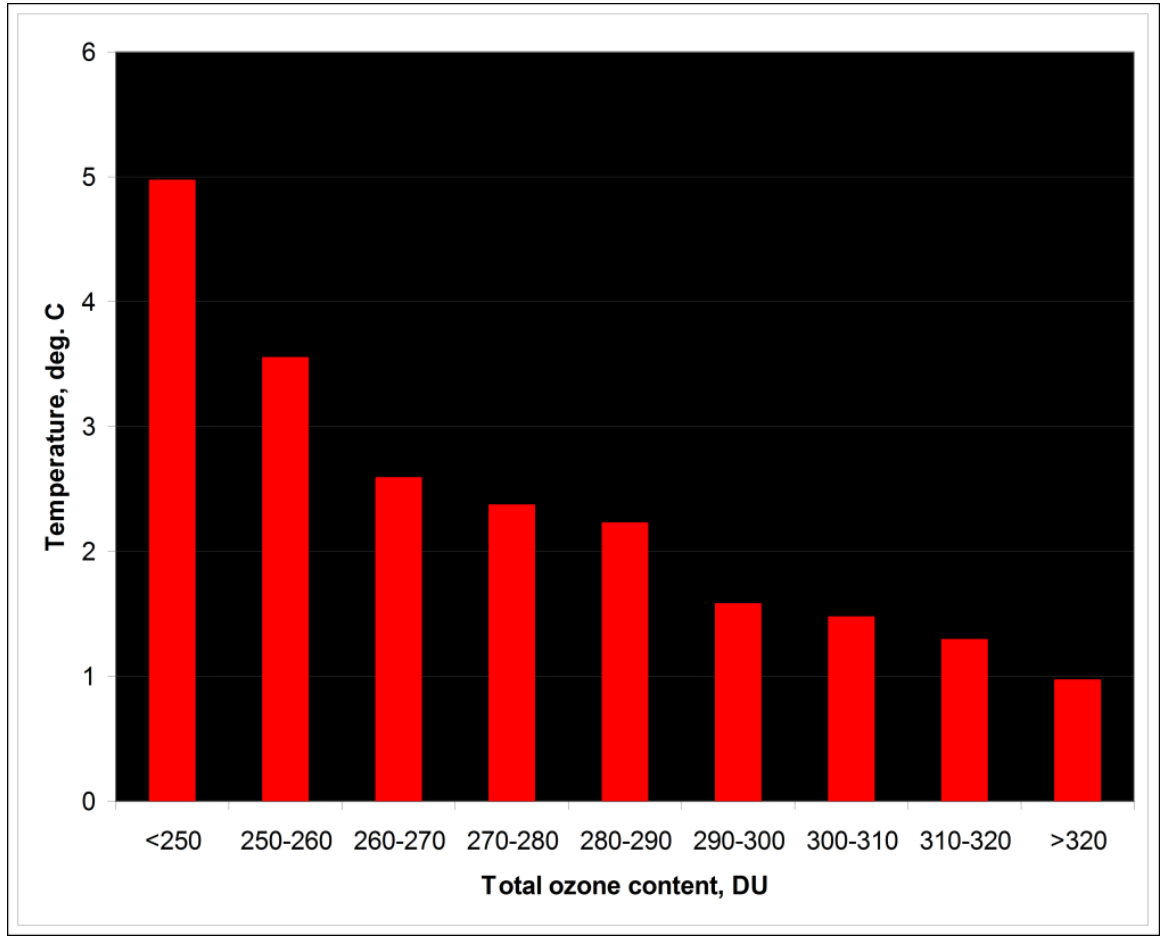

Source: Calculation according to TuTiempo.net and Goddard Space Flight Center.

Figure 15. The dependence of the maximum daily temperature of the surface layer air in December-February on the total atmospheric ozone (Antarctica, Marambio Base 19992019).

Due to hydrogen oxidation during an earthquake, atmospheric moisture content also increases, relative humidity rises to $99 \%-100 \%$, and precipitation falls.

Based on the theory of global consequences of degassing, we should expect when averaging over a large time interval a negative relationship between the maximum temperature of the surface layer air and the total atmospheric ozone content, which is determined not only by the solar radiation, but also by the lithosphere perturbations.

The predicted effect does exist (Figure 15). There are all reasons to believe that the total content of ozone in the atmosphere is an important climate-forming factor.

\section{Warm Ice}

In the annual cycle, the Antarctic sea ice usually retreats to minimum in the third decade of February (Figure 16).

Since 2016, there is a downward trend towards ice extent reduction in autumn (Figure 17).

Taking into account a certain similarity between the fluctuations of the total atmospheric ozone content and the temperature of its surface layer during hydrogen degassing, we can assume that the ocean's behavior should demonstrate similar features as well. The hypothesis will be tested using the information on extreme daily changes in the sea ice extent in 2017-2019 when warming was 


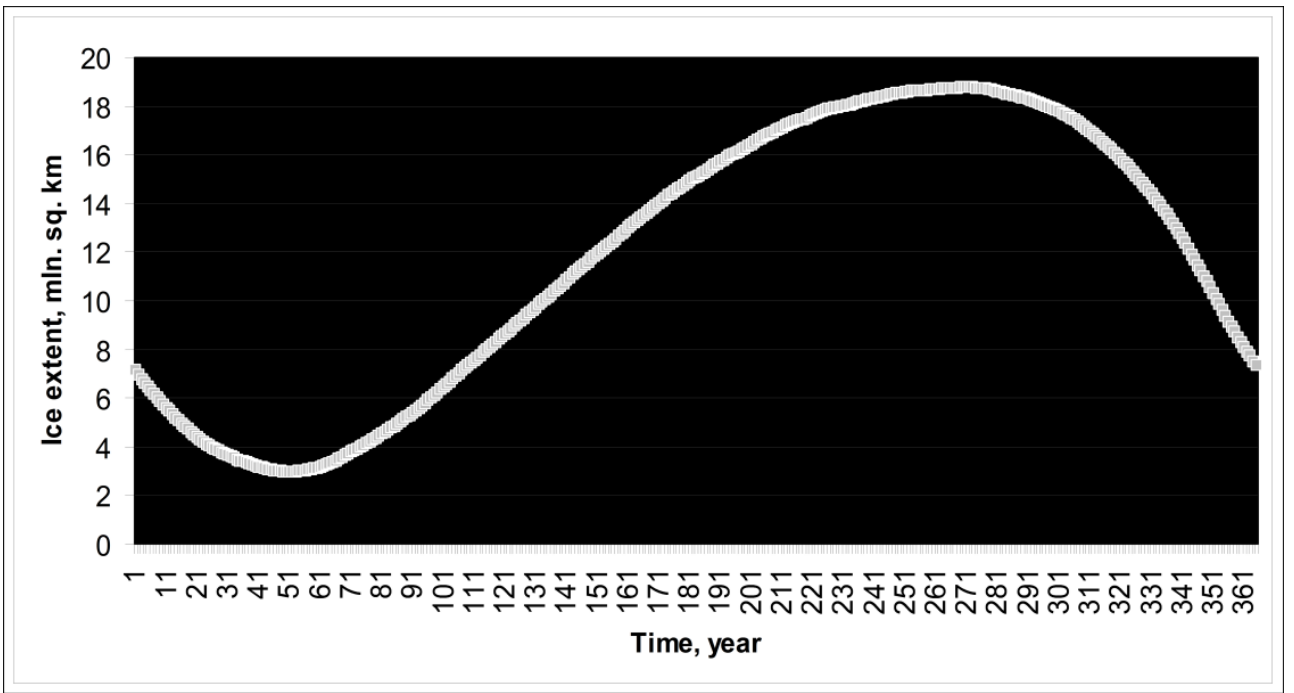

Source: National Snow \& Ice Data Center, https://nsidc.org/arcticseaicenews/antarctic-daily-image-update/.

Figure 16. Antarctic sea ice daily data in 1999-2019.

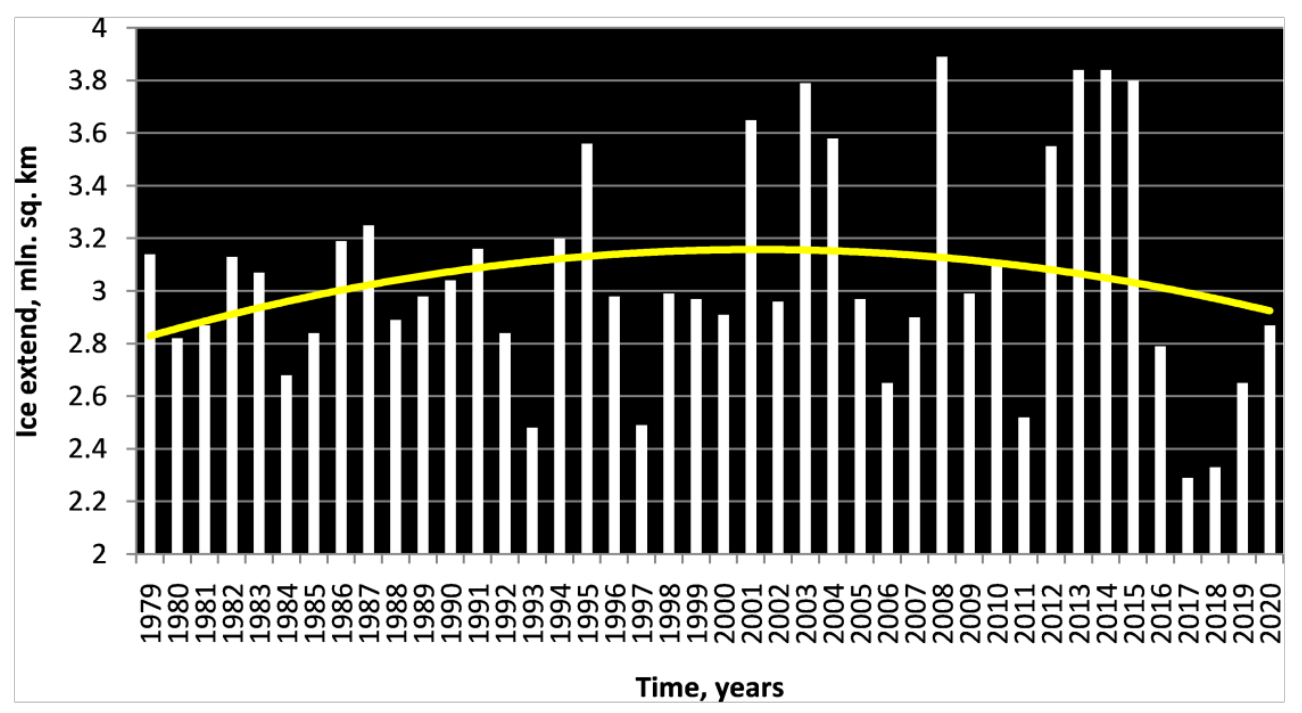

Source: ftp://sidads.colorado.edu/DATASETS/NOAA/G02135/south/monthly/data/.

Figure 17. Dynamics and trend of monthly data on Antarctic ice extent in February 1979-2020.

most significant.

Three episodes of the fastest ice melting in the summer were recorded during the periods of large negative ozone anomalies (Figures 18-20).

On the contrary, at the time of positive anomalies in the total ozone content, ice extent grows at an accelerated rate (Figures 21-23).

Antarctica demonstrates the integrity of lithosphere, hydrosphere, and atmosphere, functioning as a unified whole.

\section{The Roles of the Erebus Volcano}

The Erebus volcano is located at the intersection of tectonic faults with coordinates of $77.53^{\circ} \mathrm{S}$ and $167.17^{\circ} \mathrm{E}$. It is one of the most active volcanoes on Earth, its 


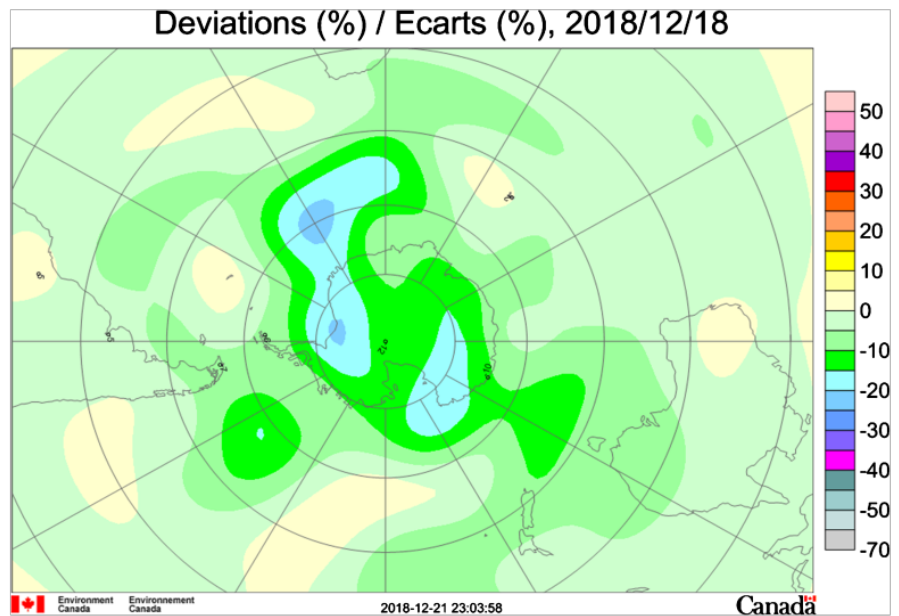

Source: Environment Canada.

Figure 18. Negative anomalies in the total atmospheric ozone content on December 18, 2018.

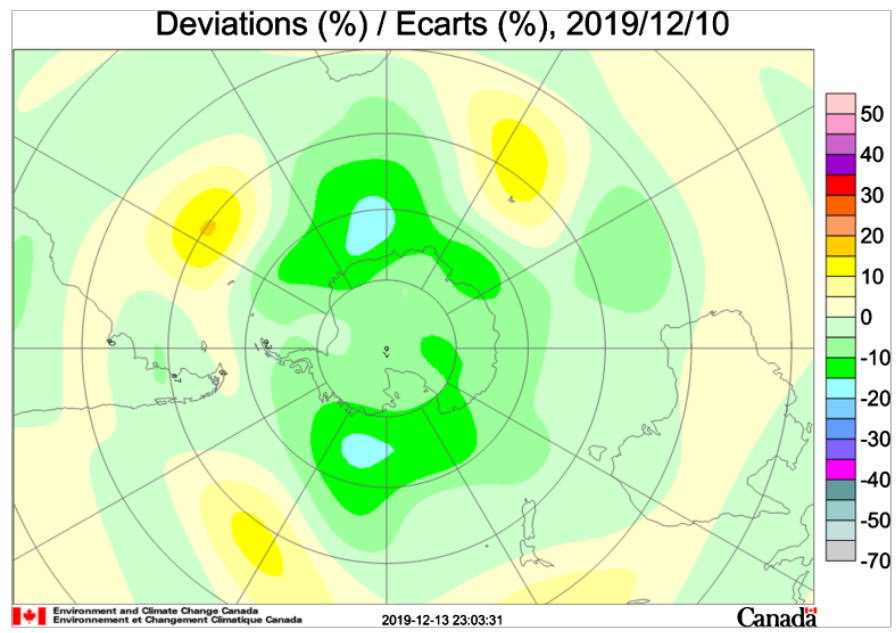

Source: Ibid.

Figure 19. Negative anomalies in the total atmospheric ozone content on December 10, 2019.

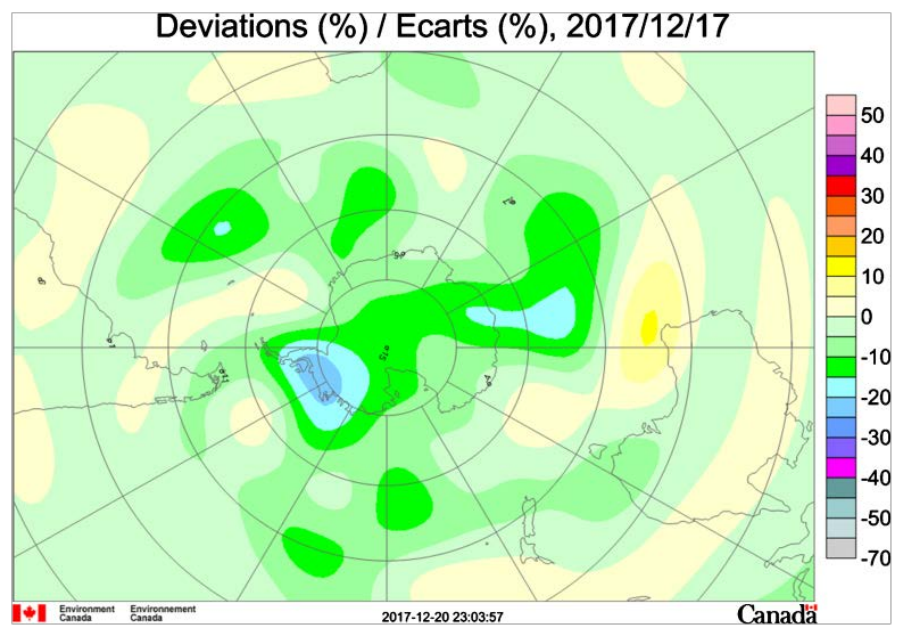

Source: Ibid.

Figure 20. Negative anomalies of the total ozone in the atmosphere on December 17, 2017. 


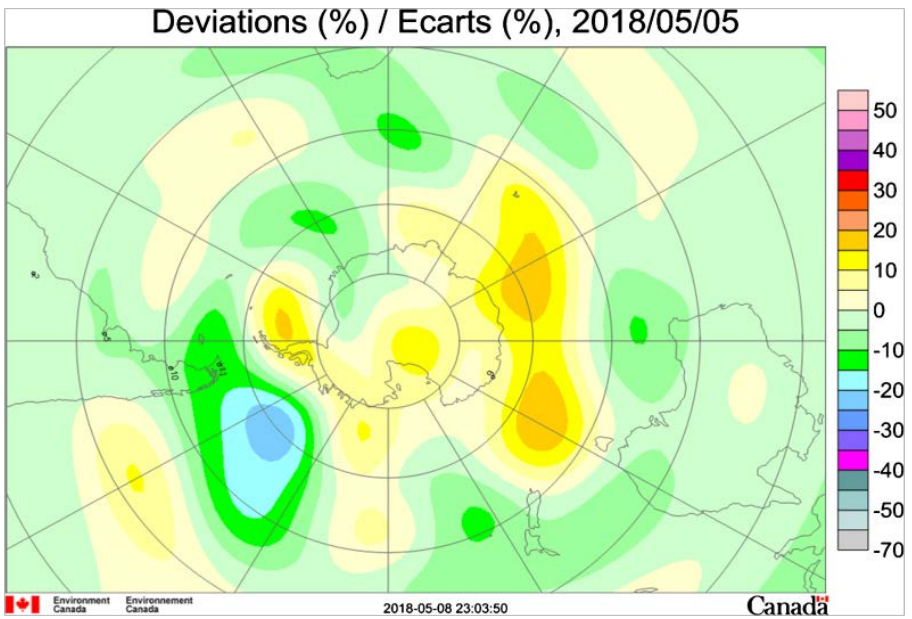

Source: Ibid.

Figure 21. Anomalies in the total atmospheric ozone content on May 5, 2018 with a daily maximum of sea ice growth.

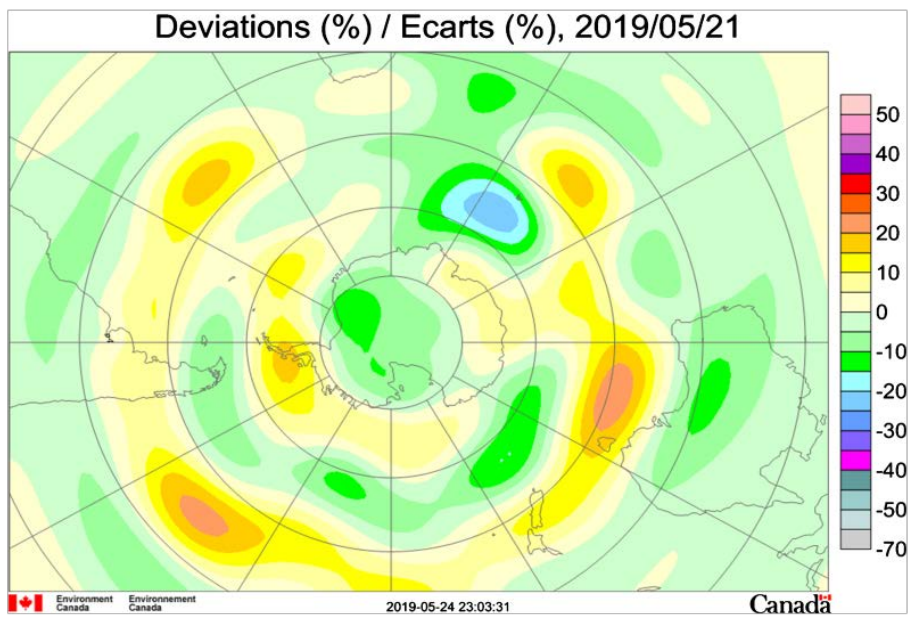

Source: Ibid.

Figure 22. Anomalies in the total atmospheric ozone content on May 21, 2019 with a daily maximum of sea ice growth.

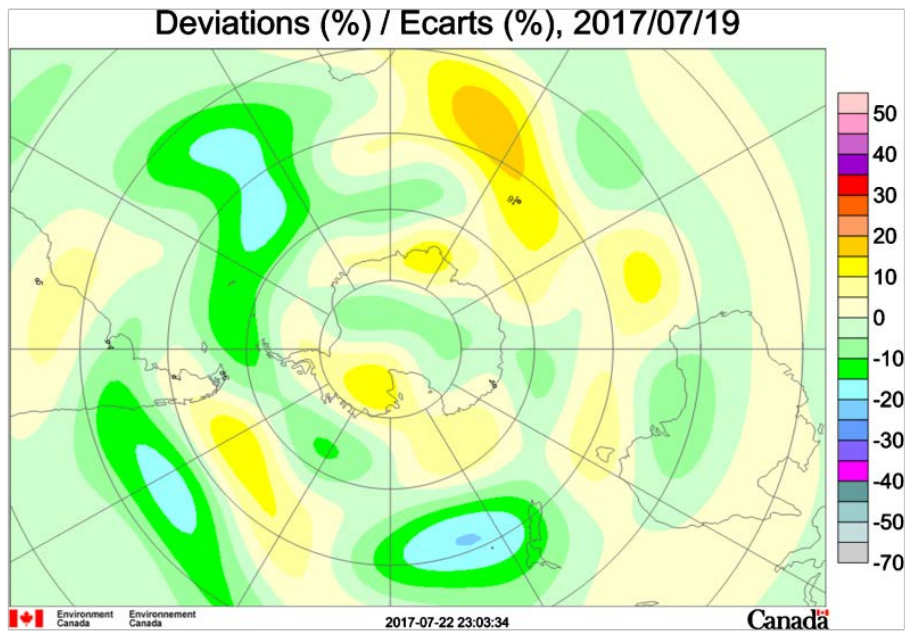

Source: Ibid.

Figure 23. Anomalies in the total atmospheric ozone content on July 19, 2017 with a daily maximum of sea ice growth. 
eruption has been ongoing continuously since 1972 accompanied by ejection of aerosols reaching a height of $8 \mathrm{~km}$, as well as emission of hydrogen (Moussallam et al., 2012) and other gases. This process can destroy the ozone layer in the stratosphere (Boichu et al., 2011; Zuev et al., 2015). According to remote monitoring data (MODVOLC Data), the situations of 2009 and 2015 differed very significantly in terms of the amount of energy generated by the volcano. Owing to this fact, we may reliably determine the contribution of deep degassing to the atmosphere. The greatest temperature contrast of the surface of lava lakes was observed in July. As expected, a high level of volcano activity in July 2009 contributed to the formation of a negative ozone anomaly in space and time (Figure 24 \& Figure 25).

The moment of a sharp increase in the eruptive activity of the volcano over the past 40 years is dated September 13, 1984. However, the amount of energy

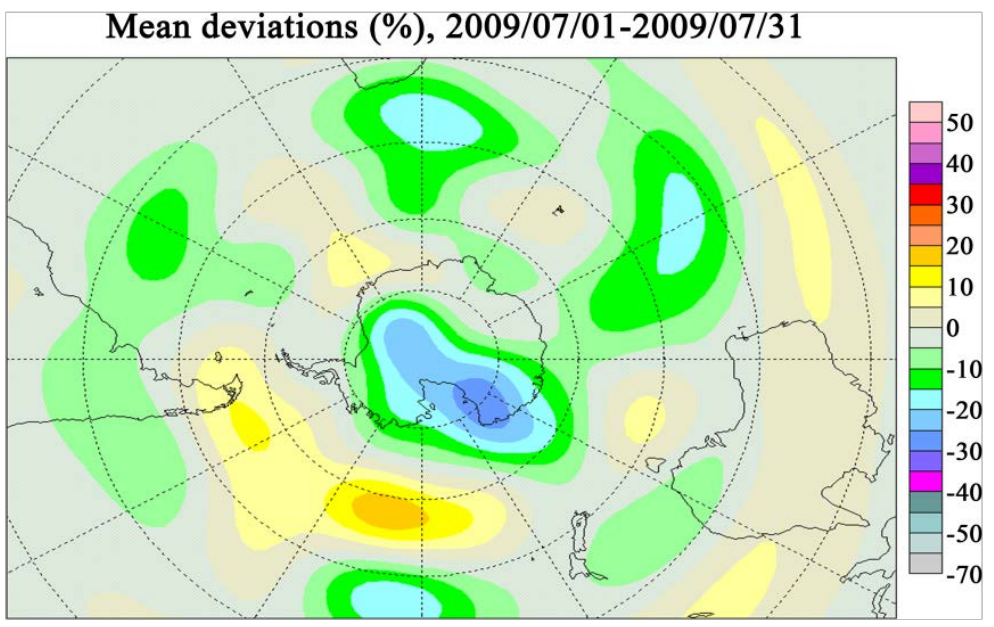

Source: Environment Canada.

Figure 24. Negative anomaly of total atmospheric ozone over the Erebus region and in the center of the continent during the period of high volcanic activity in July 2009.

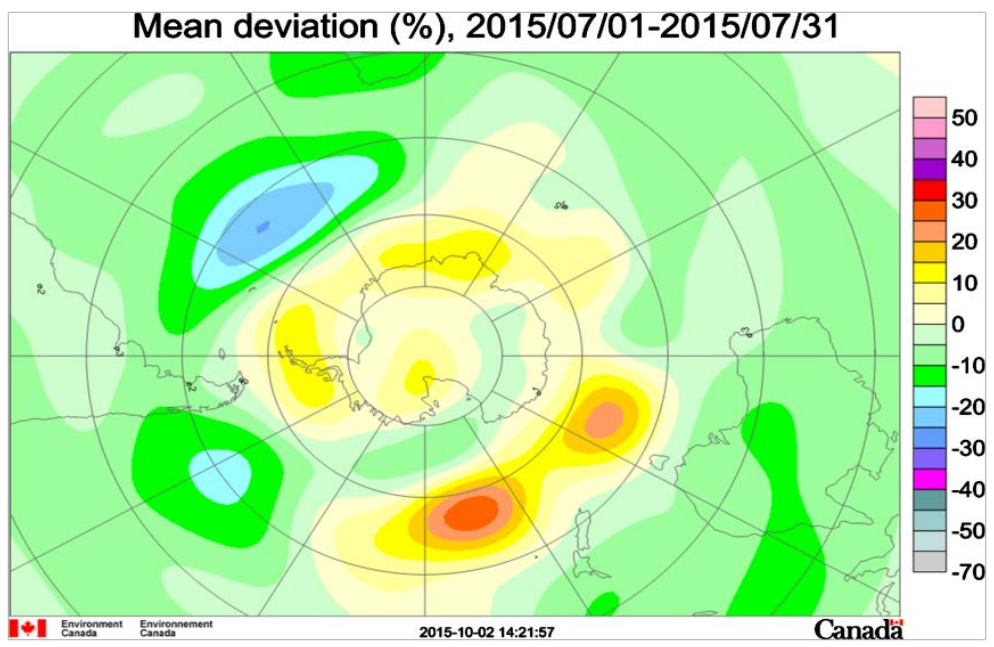

Source: Ibid.

Figure 25. Unusual development of a positive total ozone anomaly over the continent during the period of low Erebus volcano activity in July 2015. 
entering the surface of the Earth began to grow as early as on September 7. This is documented by air warming signals (by $30^{\circ}$ ) in the center of the continent (Figure 26).

Preparing for the eruption affected the state of the stratosphere over the continent, where two large ozone anomalies with the opposite sign occurred nearby (Figure 27).

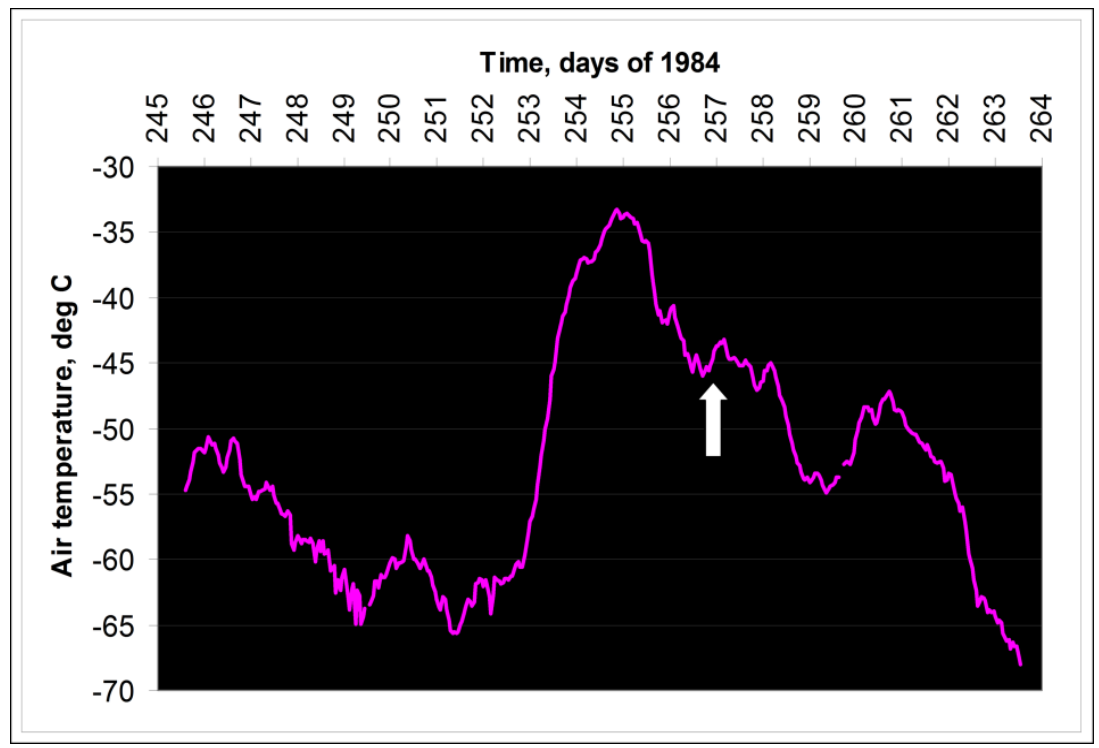

Source: According to Earth System Research Laboratory, ftp://aftp.cmdl.noaa.gov/data/meteorology/in-situ/spo/.

Figure 26. Episode of the surface air layer warming in September 1984 in the South pole, $1200 \mathrm{~km}$ from Erebus volcano (South Pole station). Activation time is indicated by an arrow.

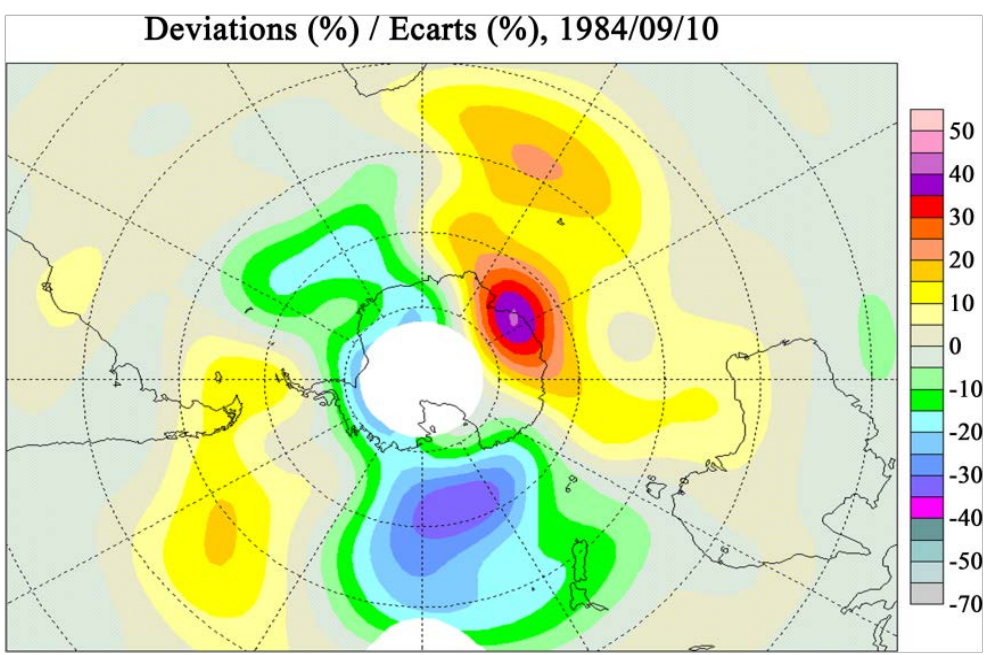

Source: Environment Canada.

Figure 27. Anomalies in the total atmospheric ozone content on September 10, 1984 before activation of the Erebus volcano.

A positive anomaly of early September of 1984 was characterized by an extremely high ozone content and a unique gradient in space (Figure 28). 
This phenomenon indicates wave-like deformations of the Earth's crust along the axis, passing through the Erebus volcano.

The peak of the 1984 eruption power was reached in December. One might think that this peak is associated with thermal anomaly in the atmosphere of the whole continent. This suggestion is justified (Figure 29).

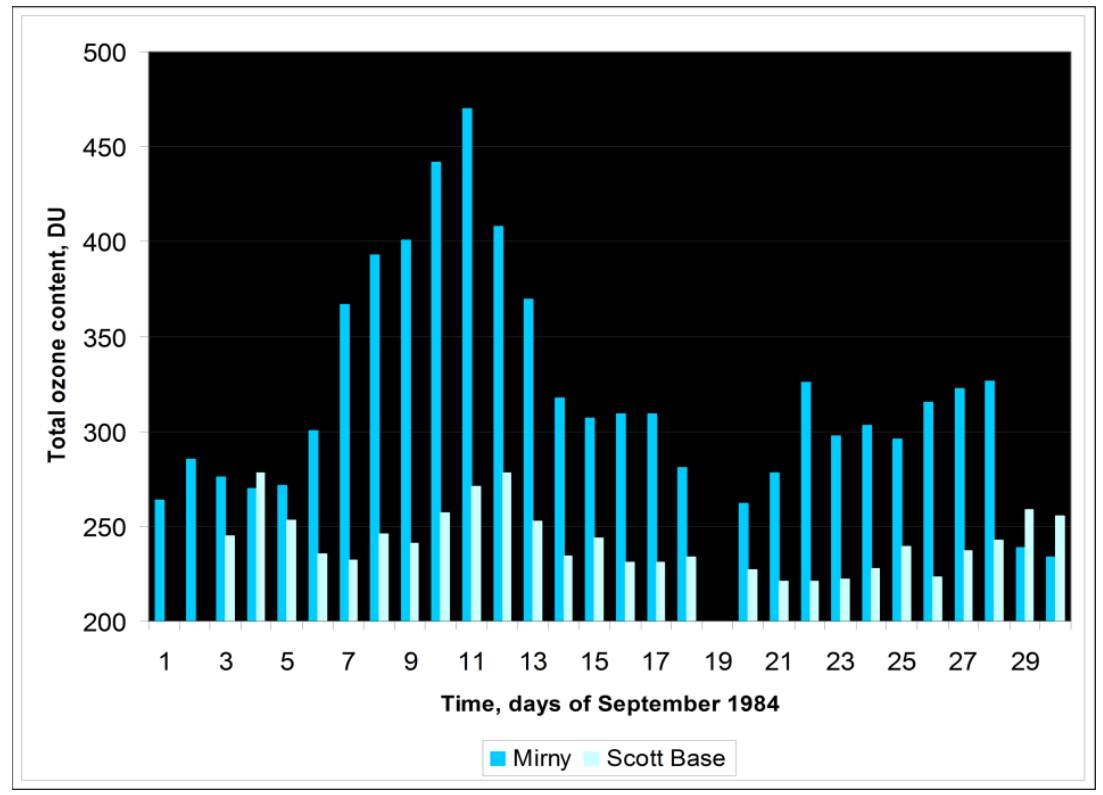

Source: According to Goddard Space Flight Center (SBUV Merged Ozone Data Set (MOD)).

Figure 28. Total atmospheric ozone content in September 1984 (Antarctic Mirny and Scott Base stations located $2500 \mathrm{~km}$ from each other).

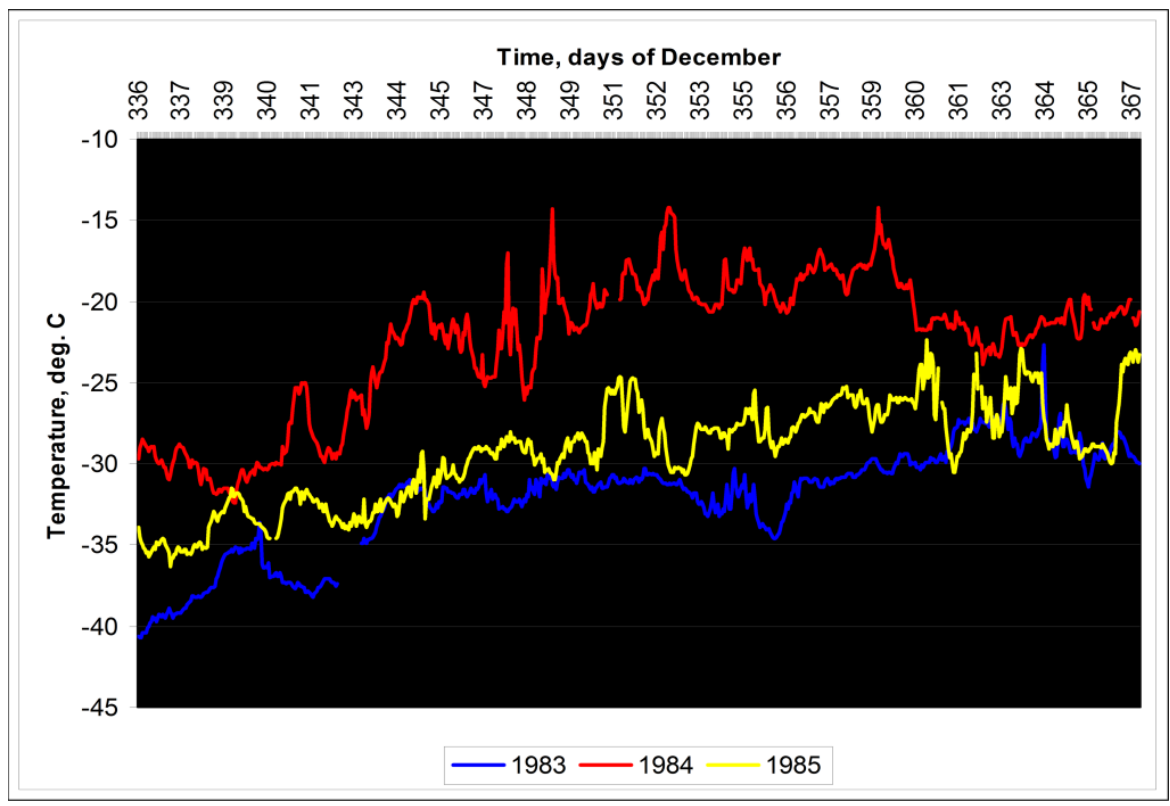

Source: According to Earth System Research Laboratory, ftp://aftp.cmdl.noaa.gov/data/meteorology/in-situ/spo/.

Figure 29. Warming of the surface air layer in December 1984 at the South Pole, $1200 \mathrm{~km}$ from Erebus volcano (South Pole station). 
The thermal anomaly coincided in time with ozone anomalies (Figure 30 ).

Thus, the Erebus volcano plays the role of a system-forming factor in the Antarctic and, at the same time, serves as an indicator of processes occurring on the planet.

\section{The Earth's Core Motion and Its Significance}

Hydrogen that heats the troposphere and the hydrosphere, and destroys the stratospheric ozone layer obviously enters the outer shells from the marginal zone between the outer liquid core of the planet and the mantle located at depths of the order of $3000 \mathrm{~km}$, i.e., about half the radius of the globe (Figure 31). If this statement corresponds to the reality, various natural anomalies caused by the increased amounts of energy coming from the subsurface should be observed at latitudes of about $60^{\circ}$ in both hemispheres.

First of all, we should talk about large-scale deformations of the lithosphere. They really concentrate at this latitude and are manifested in the reduction of the continental crust area at the projection of the contact zone of the core and mantle on the Earth's surface (Figure 32).

Studying the geography of earthquake hypocenters in temperate latitudes allows for a conclusion that they also tend toward $60^{\circ}$ parallel, since the energy

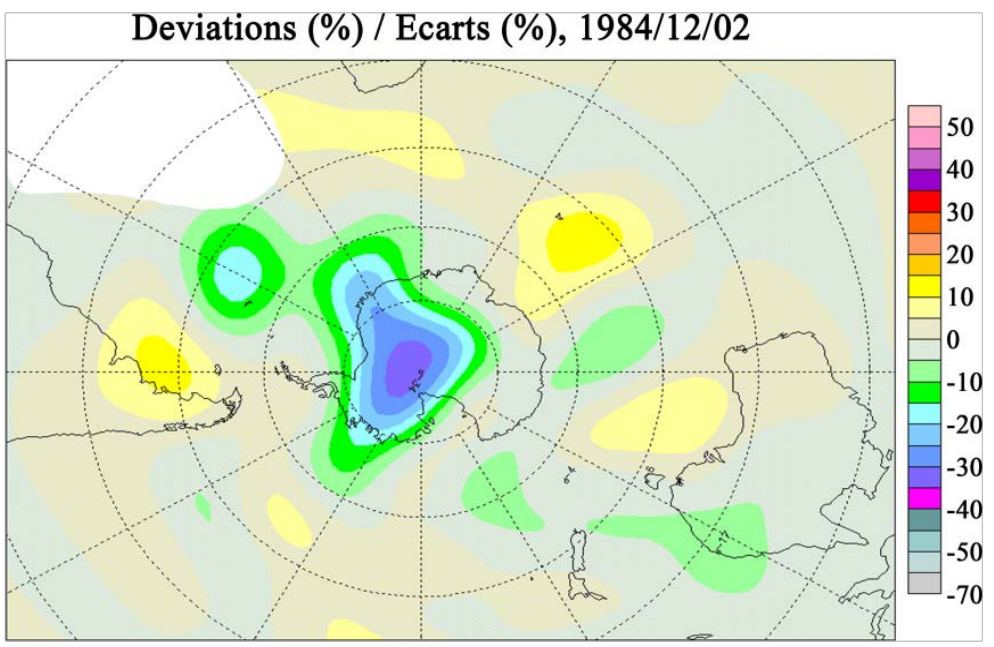

Source: Environment Canada.

Figure 30. Anomaly in the total atmospheric ozone content in December 1, 1984 during the Erebus volcano activation.

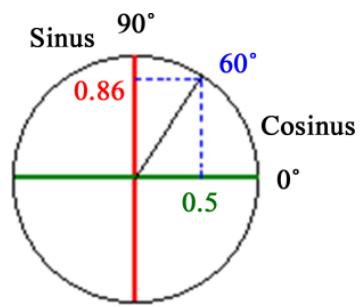

Figure 31. The geometric pattern of the projection of the planetary core on the Earth's surface is about $60^{\circ}$. 


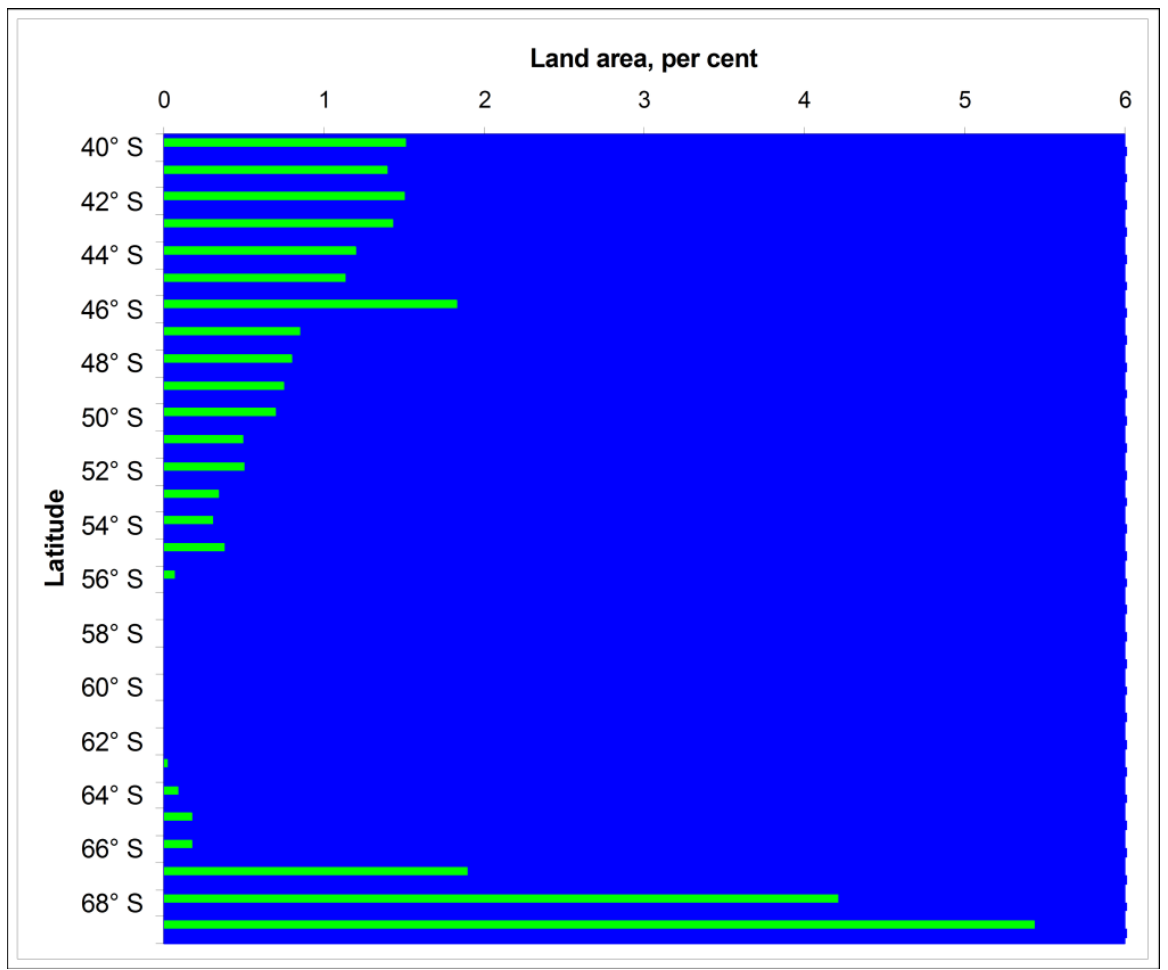

Source: The Shuttle Radar Topography Mission, http://www2.jpl.nasa.gov/srtm.

Figure 32. Land area by latitudes of the Southern Hemisphere (\% adjusted for length parallels, logarithmic scale).

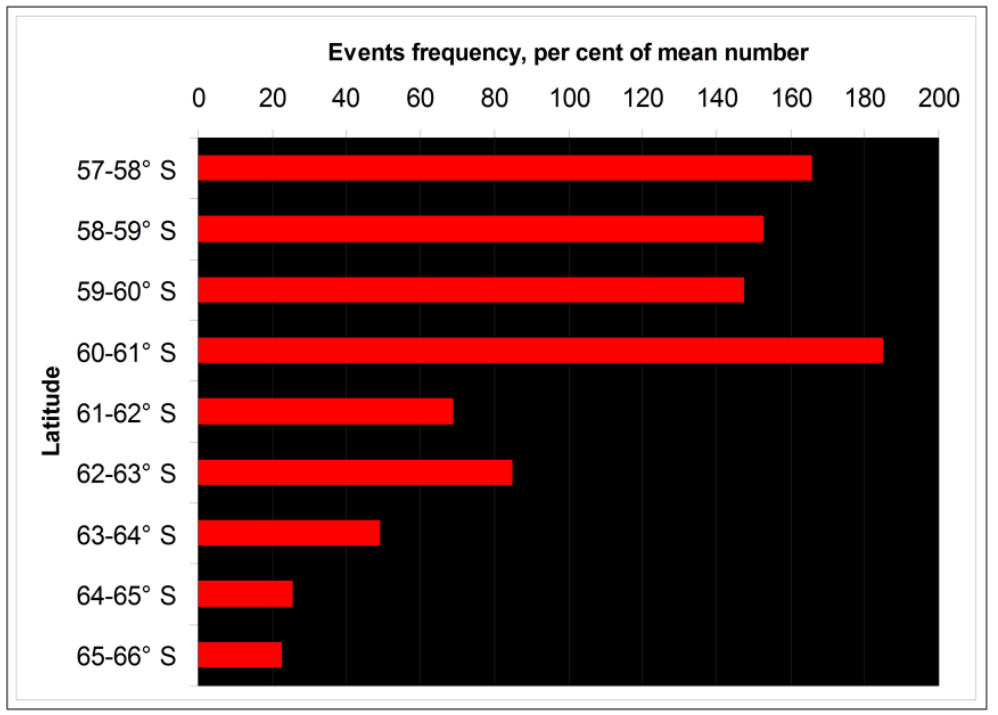

Source: Ibid.

Figure 33. The distribution of the earthquake hypocenters with $M \geq 3$ in the projection of the Earth's core in the Southern Hemisphere (averaging over 7,800 events for the period 1990-2019).

base for them is provided by it is deep hydrogen (Figure 33).

Concentrated hydrogen emissions along the parallels of $60^{\circ}$ create circular negative anomaly or ring-shaped ozone anomaly system (Figure 34 \& Figure 35). 


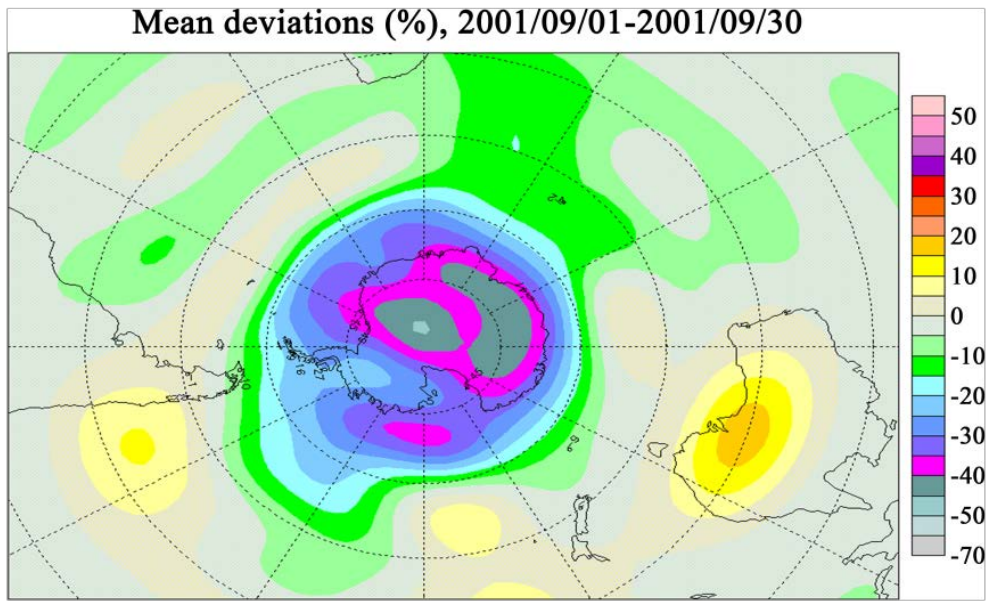

Source: Environment Canada.

Figure 34. The ozone anomaly in September 2001.

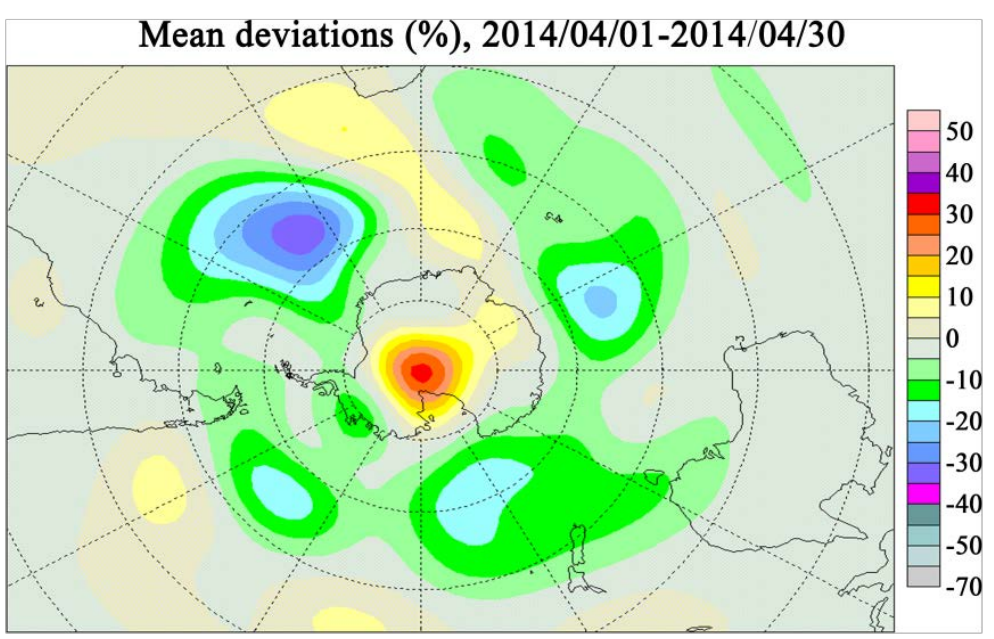

Source: Ibid.

Figure 35. The ozone anomaly in April 2014.

There is direct evidence of hydrogen entering the lithosphere and other shells precisely from the core of the Earth. We are talking about situations of acceleration or deceleration, when inertia forces cause internal stresses of the planet's body. On physical logic, the emission of deep hydrogen should increase in January-June, when the Earth moves away from the Sun, and decrease in July-December under the conditions of the Earth approach to the Sun, and this ratio persists in the months of the equinox. This regularity does actually exist (Figure 36).

In November and December, when the planet moves to the point of perihelion, the core renders pressure on the mantle of the Northern Hemisphere, as seen from the increased frequency of earthquakes. Therefore, during this period, the levels of deep hydrogen emission are different south and north of the equator (Figure 37).

When analyzing the seismic activity of the southern latitudes at the projection 


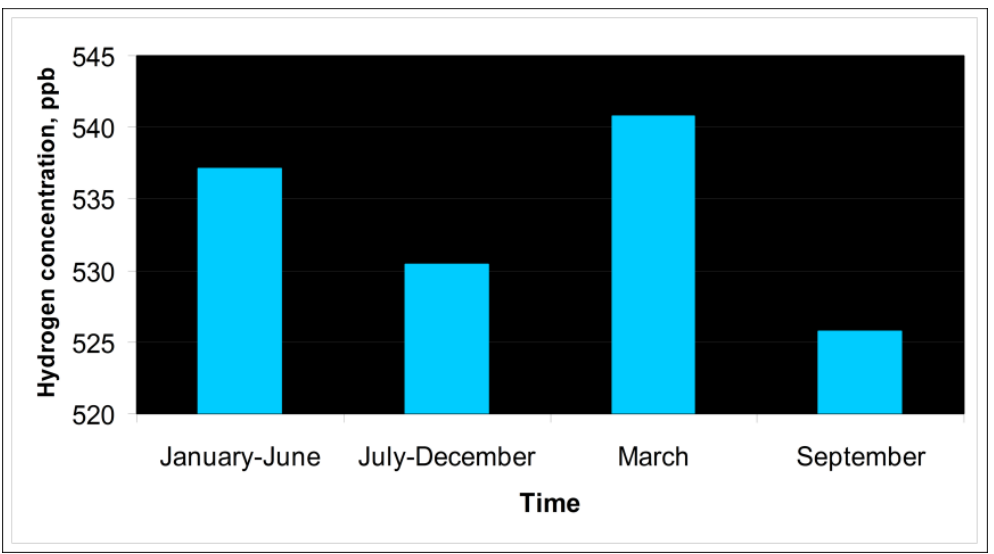

Source: Calculation according to Earth Systems Research Laboratory. Global monitoring Division, https://www.esrl.noaa.gov/gmd/dv/data/.

Figure 36. The average hydrogen content in the surface air layer near the South pole (South Pole station).

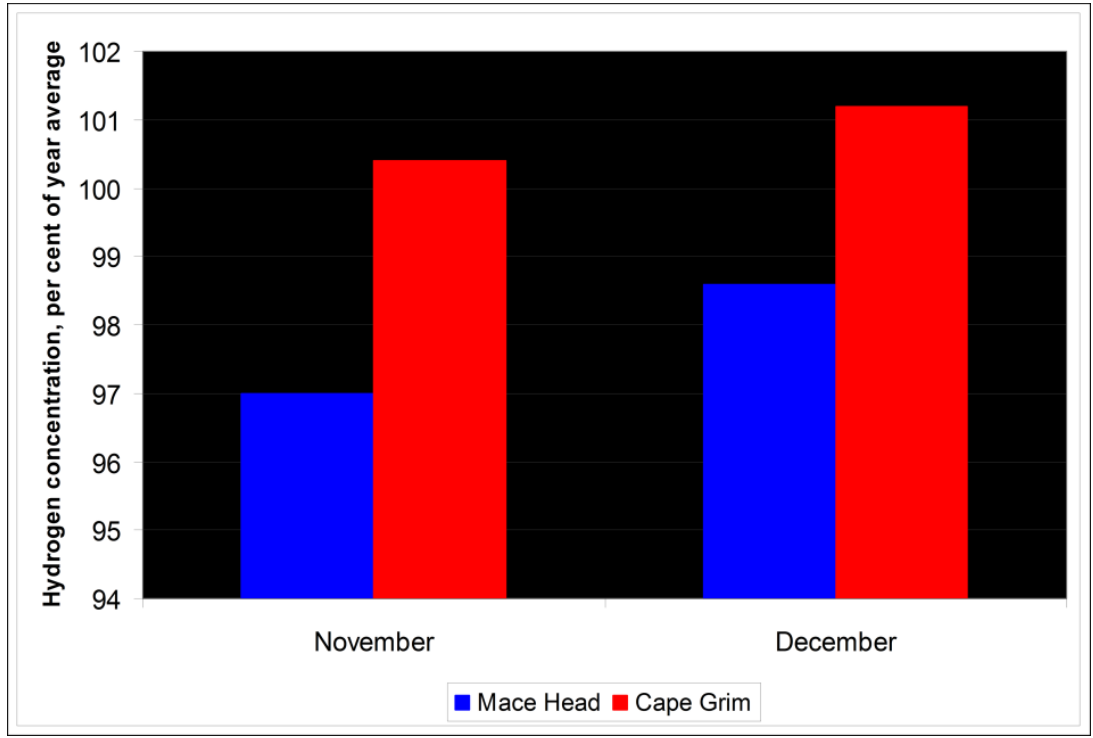

Source: The Advanced Global Atmospheric Gases Experiment (https://agage.mit.edu/data).

Figure 37. Different average monthly hydrogen concentrations in the surface air layer of the Northern and Southern hemispheres in November and December according to Mace Head (Ireland) and Cape Grim (Tasmania) stations, 1994-2019.

of the Earth's core, the consecutive minimum of 1997 and the maximum of 1998, which differ in the number of earthquakes with $M \geq 5$ by 3 , are noteworthy. It leads to the idea of fluctuations in the rate of subsoil degassing in the Antarctica. And, in actual fact, the appearance of two of the largest miscellaneous anomalies of the hydrogen content in the surface air layer were recorded at the South Pole stations during those years (Figure 38).

The atmosphere responded to the deep hydrogen entrance by sharply increased temperature (Figure 39).

The effect of degassing has spread throughout the troposphere: a rise in air temperature and an increase in its moisture content can be traced to a surface 
level of $300 \mathrm{mb}$, i.e., about $9 \mathrm{~km}$ (Figure 40 \& Figure 41).

It may well be that cases of deep hydrogen emission will be found in the context of the planet deformations manifested by the changing orientation of the rotation axis. At the same time, the geographic North Pole begins to move unevenly.

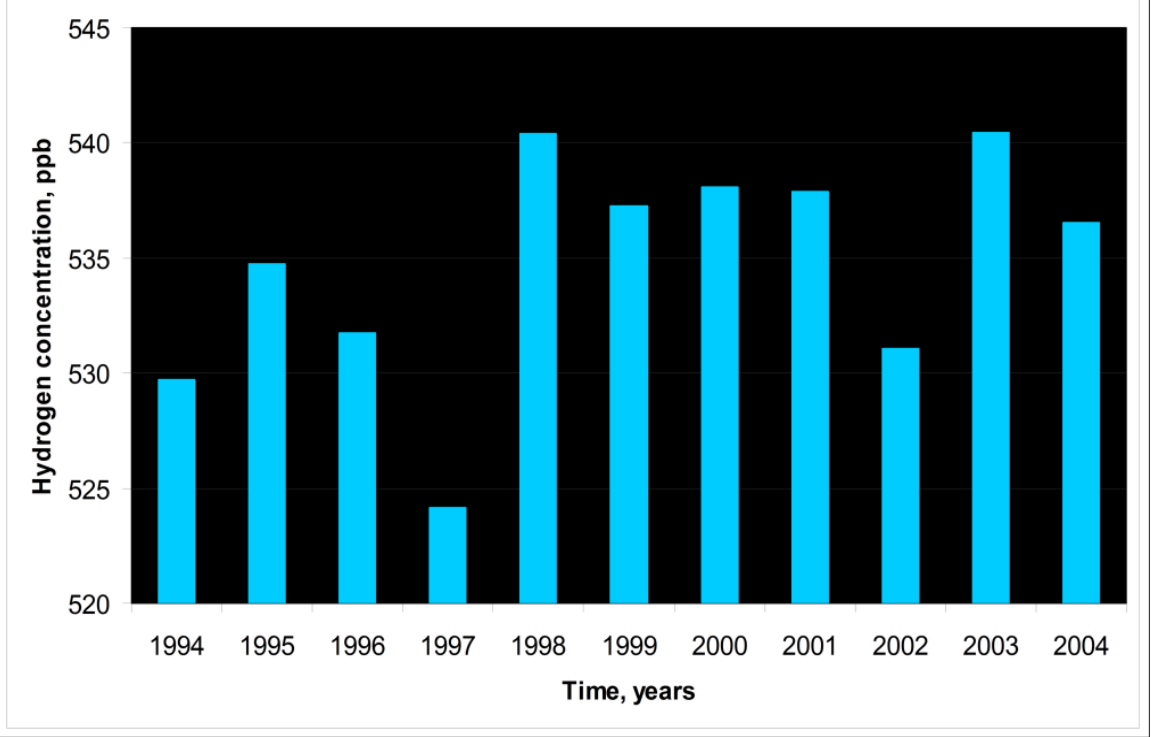

Source: Ibid.

Figure 38. The average annual hydrogen content in the surface air layer at the South Pole (South Pole Station).

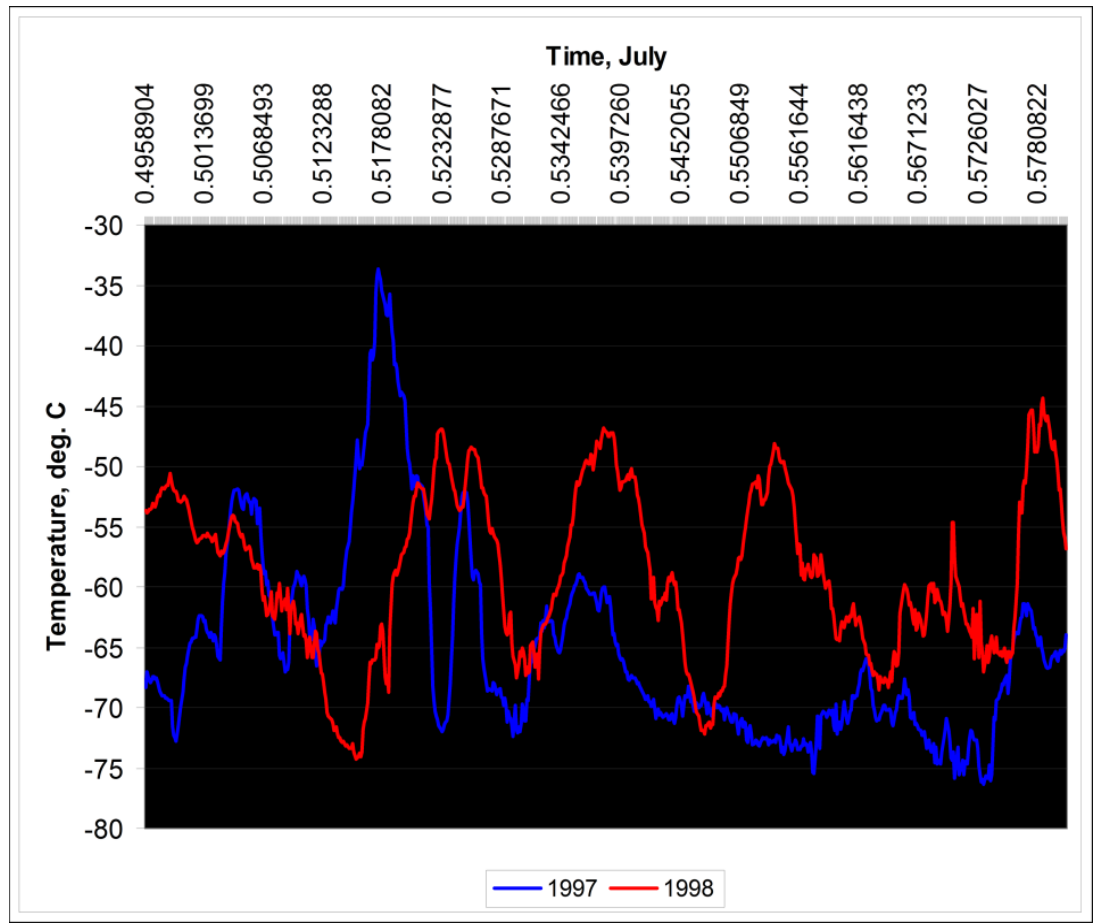

Source: Ibid.

Figure 39. The average hourly temperature of the surface air layer at the South Pole in July 1997 and 1998. 


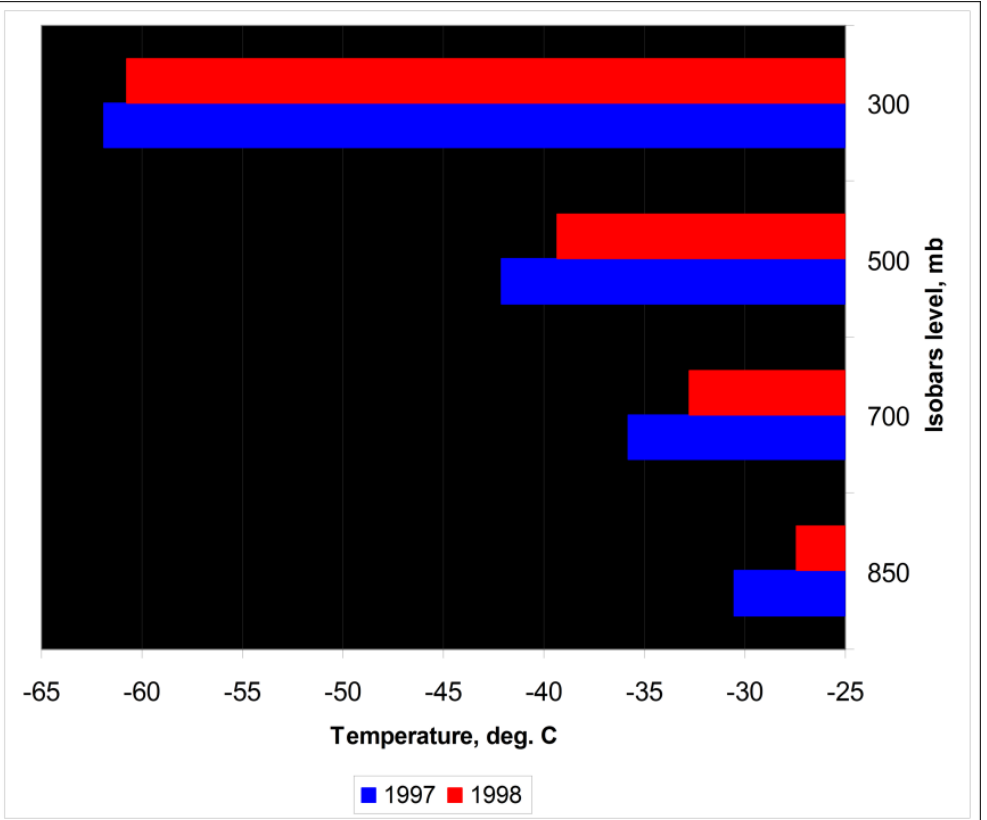

Source: Earth Systems Research Laboratory. Physical science division https://www.esrl.noaa.gov/psd/cgi-bin/data/timeseries/timeseries1.pl.

Figure 40. July air temperature over Antarctica and the shelf (from latitude $60^{\circ}$ ) with abnormally weak and strong hydrogen emissions.

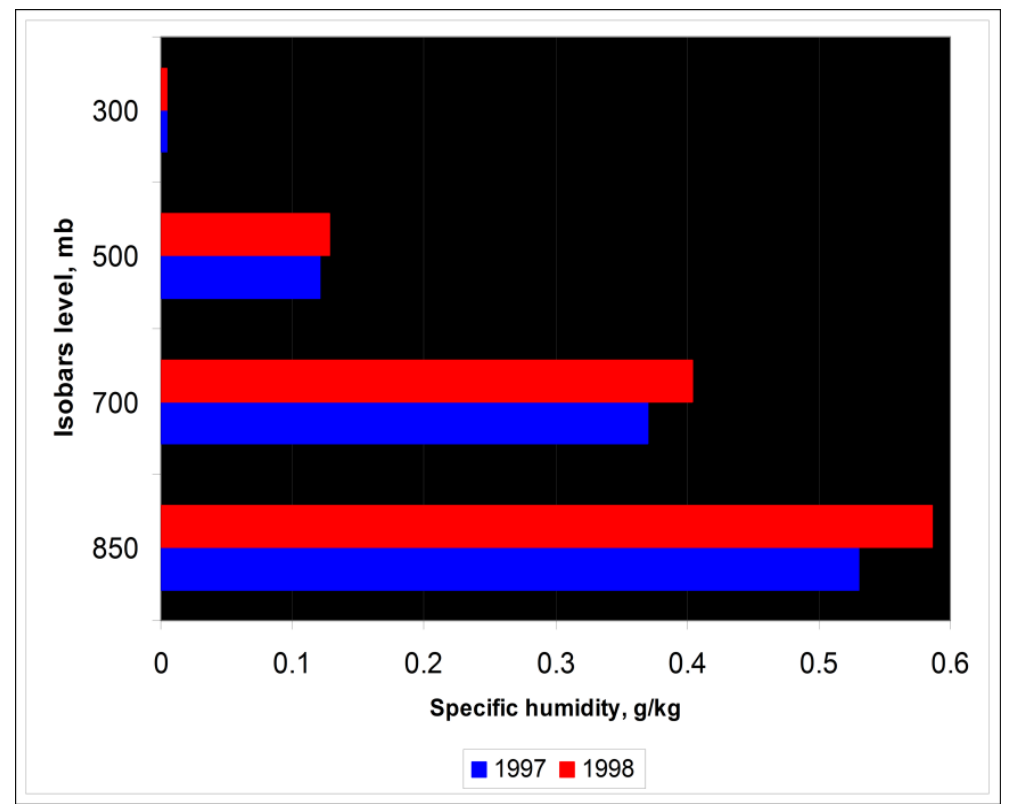

Source: Ibid.

Figure 41. The absolute humidity over Antarctica and the shelf (from latitude $60^{\circ}$ ) in July with abnormally weak and strong hydrogen emissions.

In February 2008, we have found one such moment (Figure 42).

In February, the core of the Earth drifts to the north due to the gravitational attraction of the Sun, and then its pressure on the mantle increases in the Northern Hemisphere and decreases in the Southern. In this case, the emission 
of deep hydrogen in two hemispheres should change in opposite directions, as is observed in the given graph (Figure 43).

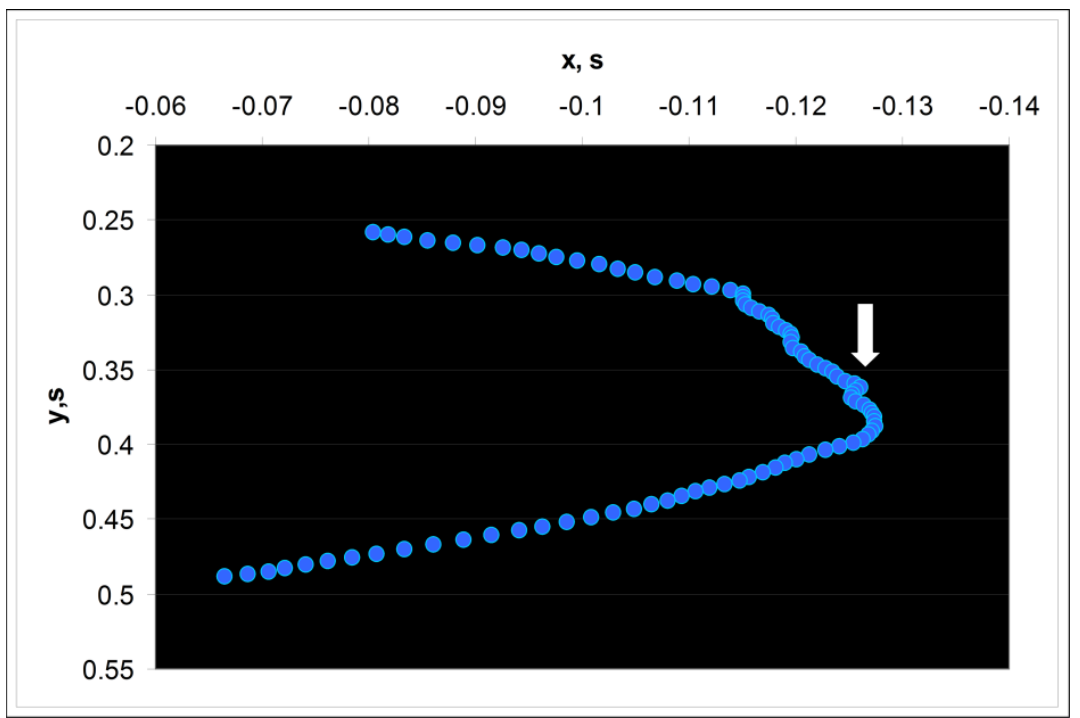

Source: According to International Earth Rotation and Reference Systems Service https://www.iers.org/IERS/EN/DataProducts/EarthOrientationData/eop.html.

Figure 42. Violation of the uniform movement of the North Pole in February 2008.

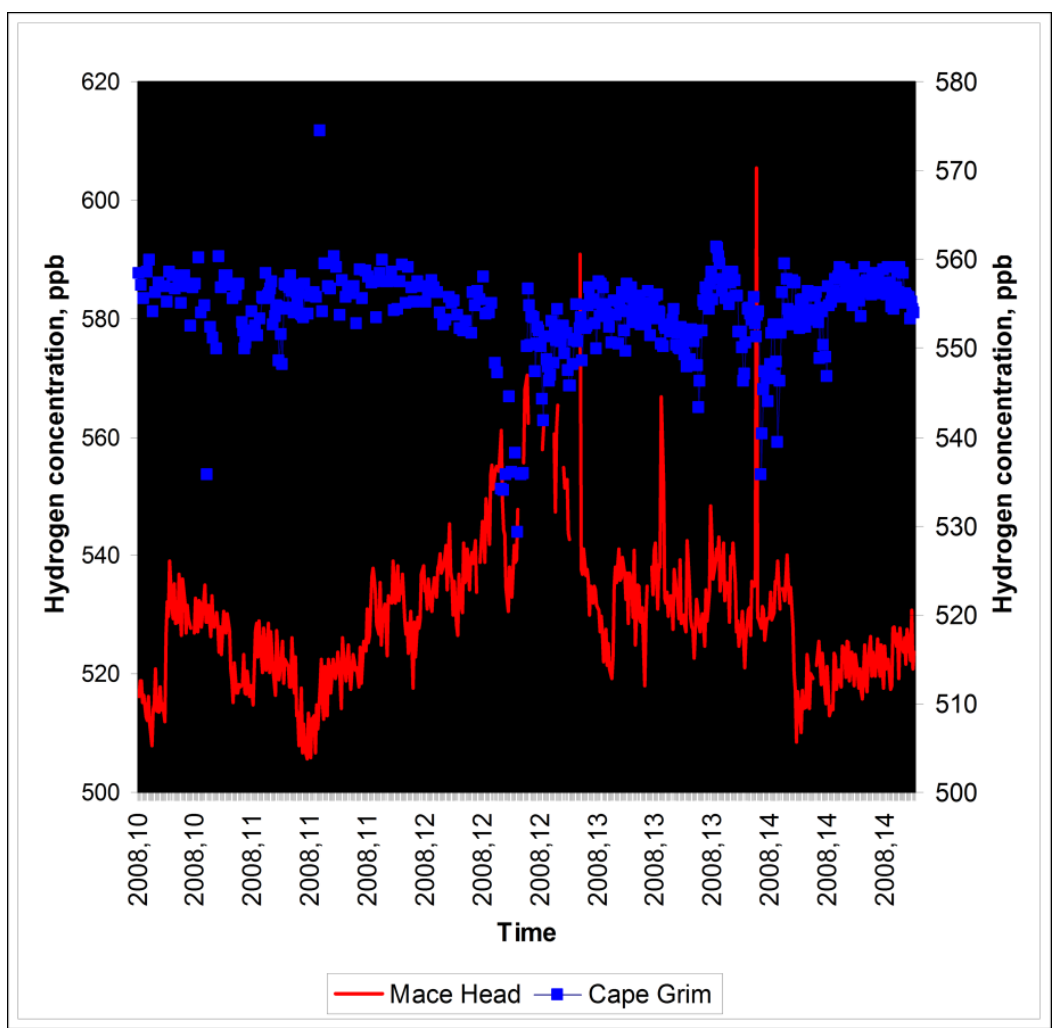

Source: According to The Advanced Global Atmospheric Gases Experiment.

Figure 43. Changes in minute concentrations of hydrogen in the surface layer of air on February 15, 2008: increase in the Northern Hemisphere (Mace Head Station, Ireland) and decrease in the southern hemisphere (Cape Grim station, Tasmania). 


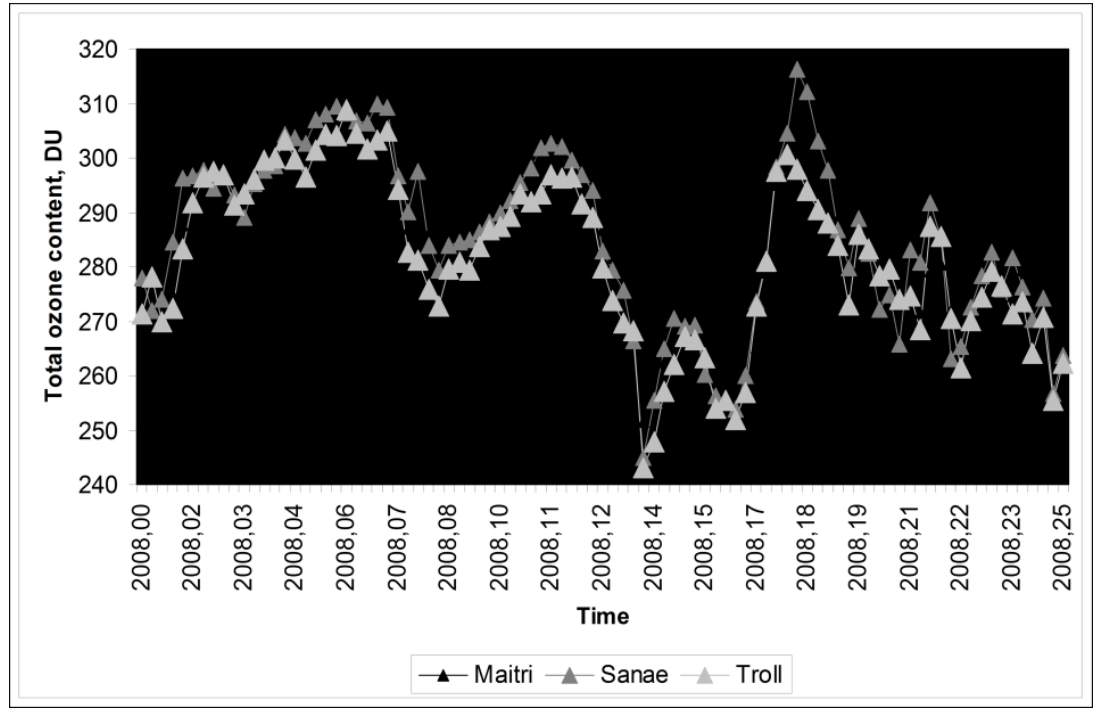

Source: According to Goddard Space Flight Center (SBUV Merged Ozone Data Set, MOD).

Figure 44. Observations of total atmospheric ozone Antarctic stations in 2008.

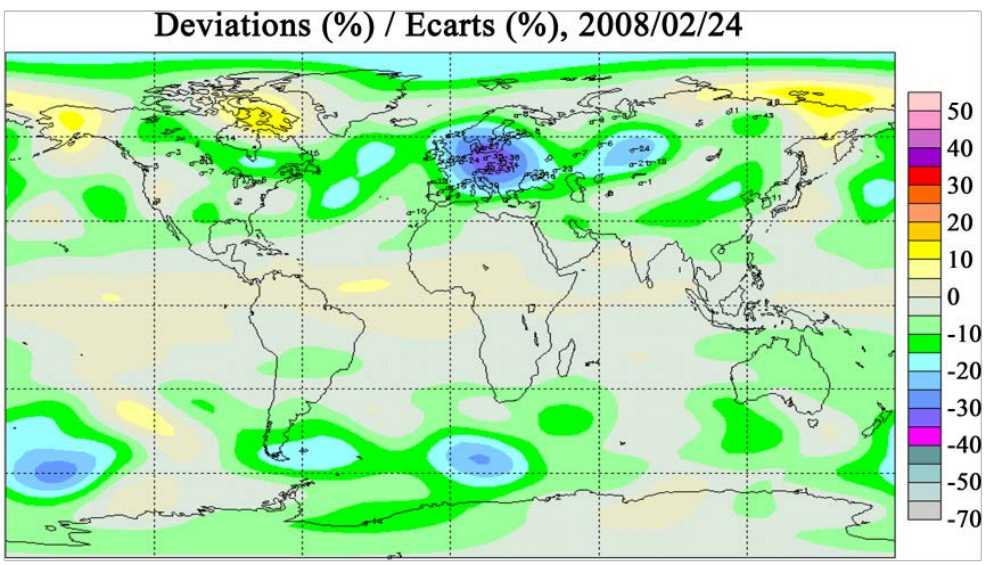

Source: Environment Canada.

Figure 45. Symmetry of anomalies in total ozone content during the 2008 event.

February 2008 was marked by the formation of large ozone anomalies in Antarctica (Figure 44).

The global nature of the 2008 event is also indicated by the symmetrical position of negative ozone anomalies at a parallel of $60^{\circ}$. Two of them are located in Europe and in the King Haakon VII Sea, near the meridian that runs through the center of the continental hemisphere through the third axis of the Earth at $12^{\circ} \mathrm{E}$, and one anomaly of the southern hemisphere is located on the same median meridian at $180^{\circ}$ from the other (Figure 45).

Taken together, these facts allow a conclusion about the long-range action of the Earth's core, which is endowed with a sun-like matter.

\section{Conclusion}

Although so remote from civilization, Antarctica, without exaggeration, should 
be regarded as a global hotbed where the most important biosphere events take place. This may be explained by the concentration of subsoil energy in the geographic South pole, where we see how Earth expansion proceeds at the maximum speed. Against the background of directed changes in all geospheres, short-term synchronous disturbances periodically arise, and the nature of these disturbances requires clarification. An equally significant task is to study the response of living organisms to the events of recent decades.

\section{Conflicts of Interest}

The author declares no conflicts of interest regarding the publication of this paper.

\section{References}

Barkin, Y. V. (2016). The Forced Relative Displacements of Shells of Planets and Satellites as the Main Mechanism for Variation of Their Natural Processes. Astronomical and Astrophysical Transactions, 29, 375-386. https://ui.adsabs.harvard.edu/abs/2016A\%26AT...29..377B/abstract

Boichu, M., Oppenheimer, C., Roberts, T. J., Tsanev, V., \& Kyle, P. R. (2011). On Bromine, Nitrogen Oxides and Ozone Depletion in the Tropospheric Plume of Erebus Volcano (Antarctica). Atmospheric Environment, 45, 3856-3866. https://doi.org/10.1016/j.atmosenv.2011.03.027

Dalziel, I. W. D. (2006). On the Extent of the Active West Antarctic Rift System. Terra Antartica Reports, 12, 193-202. https://www.researchgate.net/publication/234039048_On_the_Extent_of_the_Active_ West_Antarctic_Rift_System

Iverson, N. A., Lieb-Lappen, R., Dunbar, N. W., Obbard, R., Kim, E., \& Golden, E. (2017). The First Physical Evidence of Subglacial Volcanism under the West Antarctic Ice Sheet. Scientific Reports, 7, Article No. 11457. https://doi.org/10.1038/s41598-017-11515-3 https://www.nature.com/articles/s41598-017-11515-3

Kalberg, T., Gohl, K., Eagles, G., \& Spiegel, C. (2015). Rift Processes and Crustal Structure of the Amundsen Sea Embayment, West Antarctica, from 3D Potential Field Modelling. Marine Geophysical Research, 36, 263-279. https://epic.awi.de/id/eprint/38721 https://doi.org/10.1007/s11001-015-9261-0

Loose, B., Garabato, A. C. N., Schlosser, P., Jenkins, W. J., Vaughan, D., \& Heywood, K. J. (2018). Evidence of an Active Volcanic Heat Source beneath the Pine Island Glacier. Nature Communication, 9, Article No. 2431.

https://doi.org/10.1038/s41467-018-04421-3

https://www.nature.com/articles/s41467-018-04421-3

MODVOLC Data. http://modis.higp.hawaii.edu/contents.html

Moussallam, Y., Oppenheimer, C., Aiuppa, A., Giudice, G., Moussallam, M., \& Kyle, P. R. (2012). Hydrogen Emissions from Erebus Volcano, Antarctica. Bulletin of Volcanology, 74, 2109-2120. https://doi.org/10.1007/s00445-012-0649-2 https://link.springer.com/article/10.1007/s00445-012-0649-2

Seroussi, H., Ivins, E., Wiens, D. A., \& Bondzio, J. (2017). Influence of a West Antarctic Mantle Plume on Ice Sheet Basal Conditions. Journal of Geophysical Research: Solid Earth, 122, 7127-7155. https://doi.org/10.1002/2017JB014423 
Syvorotkin, V. L. (2010). Hydrogen Degassing of the Earth: Natural Disasters and the Biosphere. In I. V. Florinsky (Ed.), Man and the Geosphere (pp. 199-204). New York: Nova Science Publishers.

Van Wyk de Vries, M., Bingham, R. G., \& Hein, A. S. (2017). A New Volcanic Province: An Inventory of Subglacial Volcanoes in West Antarctica. Geological Society, London, Special Publications, 461, 231-248. https://doi.org/10.1144/SP461.7

Zuev, V. V., Savelieva, E. S., Zueva, N. E., \& Gerasimov, V. V. (2015). The Antarctic Ozone Depletion Caused by Erebus Volcano Gas Emissions. Atmospheric Environment, 122, 393-399. https://doi.org/10.1016/j.atmosenv.2015.10.005

https://www.sciencedirect.com/science/article/pii/S1352231015304246 